\title{
A DEMANDA DE AUTOMÓVEIS NO BRASIL: UMA ANÁLISE A PARTIR DE EFEITOS REGIONAIS
}

Adirson Maciel de Freitas Junior ${ }^{1}$ Cleise Maria Tupich Hilgemberg ${ }^{2}$

Resumo: O presente trabalho investigou a demanda de automóveis por mil habitantes nas microrregiões brasileiras por meio dos processos de convergência absoluta e condicional além de testar a hipótese da existência de clubes de convergência, no período 2004 a 2015. Investigou também, os efeitos regionais da redução do IPI (Impostos sobre Produto Industrializado) com o objetivo de identificar se o consumo de automóveis por mil habitantes a nível de regional sofreu alteração no período de atuação dessa política (2008 a 2014), em relação ao período anterior (2004 a 2007), os resultados foram obtidos por meio do uso de ferramentas de Análise Exploratória de Dados Espaciais (AEDE) e da Econometria Espacial. As estimações indicaram que microrregiões que apresentaram uma menor demanda efetiva por mil habitantes no período inicial (2004-2007) tenderam a ter maiores taxas de crescimento de suas frotas de automóveis no período posterior (20082014), evidenciando assim, um processo de homogeneização ao longo do território brasileiro. Ademais, os resultados indicam existência de dois clubes de convergência denominados de norte e sul, os quais apresentaram características distintas. Por fim, as variáveis estruturais mostraram-se satisfatórias tendo seu grau de significância em 1\%. Esses resultados corroboram com aqueles encontrados pelos autores Cintra (2014), Haddad (2015), Lucinda (2017), que identificaram externalidades positivas do aumento da frota de automóveis e que têm o potencial de alavancar o dinamismo nas regiões vizinhas.

Palavras-chave: Demanda Efetiva de Automóveis. Imposto sobre Produto Industrializado. Análise Exploratória de Dados Espaciais (AEDE). Painel Espacial. Convergência.

\section{THE DEMAND OF AUTOMOBILES IN BRAZIL: AN ANALYSIS FROM REGIONAL EFFECTS}

Abstract: The present work investigated the demand for automobiles per thousand inhabitants in the Brazilian micro-regions through the processes of absolute and conditional convergence in addition to testing the hypothesis of the existence of convergence clubs, in the period 2004 to 2015 . It also investigated the regional effects of the reduction of the IPI (Taxes on Industrialized Product) with the objective of identifying whether the consumption of automobiles per thousand inhabitants at regional level has changed in the period of operation of this policy (2008 to 2014), in relation to the previous period (2004 to 2007), results were obtained through the use of Exploratory Spatial Data Analysis (ESDA) and Spatial Econometrics tools. Estimates indicated that micro-regions that had a lower effective demand per thousand inhabitants in the initial period (2004-2007) tended to have higher growth rates for their automobile fleets in the subsequent period (2008-2014). Furthermore, the results indicate the existence of two convergence clubs, named North and South, which presented different characteristics. Finally, the structural variables proved to be satisfactory with a $1 \%$ degree of significance. These results corroborate those found

\footnotetext{
${ }^{1}$ Universidade de São Paulo, Piracicaba, Brasil, adirson52@gmail.com, https://orcid.org/0000-00033868-0235

2 Universidade Estadual de Ponta Grossa, Departamento de Economia, Ponta Grossa, Brasil, cmatupich@gmail.com, https://orcid.org/0000-0002-4743-0089
} 
by the authors Cintra (2014), Haddad (2015), Lucinda (2017), who identified positive externalities of the increase in the car fleet and which have the potential to leverage dynamism in neighbouring regions.

Palavras-Chave: Effective Demand of Cars. Industrialized Product Tax. Exploratory Spatial Data Analysis (ESDA). Space Panel. Convergence.

\section{LA DEMANDA DE AUTOMÓVILES EN BRASIL: UN ANÁLISIS DE LOS EFECTOS REGIONALES}

Resumen: El presente trabajo investigó la demanda de automóviles por mil habitantes en las microrregiones brasileñas a través de los procesos de convergencia absoluta y condicional, además de probar la hipótesis de existencia de clubes de convergencia, en el período 2004 a 2015. También investigó la efectos regionales de la reducción del IPI (Impuestos al Producto Industrializado) con el objetivo de identificar si el consumo de automóviles por mil habitantes a nivel regional ha variado en el período de vigencia de esta política (2008 a 2014), en relación a la período anterior (2004 a 2007), los resultados se obtuvieron mediante el uso de herramientas de Análisis Exploratorio de Datos Espaciales (AEDE) y Econometría Espacial. Las estimaciones indicaron que las microrregiones que tuvieron menor demanda efectiva por mil habitantes en el período inicial (2004-2007) tendieron a tener mayores tasas de crecimiento de sus flotas de automóviles en el período posterior (2008-2014), evidenciando así un proceso de homogeneización. en todo el territorio brasileño. Además, los resultados indican la existencia de dos clubes de convergencia denominados Norte y Sur, que tenían características diferentes. Finalmente, las variables estructurales resultaron satisfactorias, con un grado de significancia del 1\%. Estos resultados corroboran los encontrados por los autores Cintra (2014), Haddad (2015), Lucinda (2017), quienes identificaron externalidades positivas del aumento del parque automotor y que tienen potencial para apalancar el dinamismo en las regiones vecinas.

Palabras clave: Demanda efectiva de automóviles.Impuesto sobre producto industrializado. Análisis exploratorio de datos espaciales (AEDE). Panel espacial. Convergencia.

\section{Introdução}

A demanda de automóveis para uma população surge da necessidade de mobilidade, a mobilidade por sua vez é de fundamental importância nos grandes centros urbanos do Brasil e do mundo, dado que a vida moderna é basicamente fundada na cidade onde habitam a maior parte dos cidadãos de um país (COSTA et al., 2007; LIMA, 2005, LUBECK, 2014; DE FÁTIMA FIGUEIRÊDO, 2013).

No Brasil, a mobilidade urbana pode ser considerada, conforme argumentam os autores Costa et al. (2007) e Duarte et al. (2012), como a condição criada para que as pessoas possam se locomover entre diferentes zonas de uma cidade ou região. É importante retratar que os sistemas de transportes são complexos e tal complexidade deriva das características estruturais existentes em cada região como 
diferenças de topografia, tipo de rodovias, renda, concentração populacional, hábitos, finalidade do consumo, organizações envolvidas em seu planejamento e gestão entre outros (CORREA, 1989).

Os sistemas de transportes, são compostos de diferentes formas, onde as mais comuns são: a pé, de bicicleta, de automóvel, por meio de transportes coletivos como ônibus, vans, trens, entre diversos outros. Esse trabalho buscara analisar em especifico a demanda pelo automóvel, que por sua vez, é um bem que compõe as cestas de consumo das famílias e esta "demanda de automóveis" como qualquer outro bem na economia é influenciada pelo preço, em outras palavras, o consumo desse bem depende das condições financeiras das famílias em adquiri-lo. Nesse sentido, de acordo com Lubeck (2014), houve um aumento na demanda por automóveis entre os anos de 2004 e 2010, esse aumento deve-se ao fato de 32 milhões de pessoas terem se elevado socioeconomicamente, fato este atribuído a estabilidade econômica, queda da inflação e diminuição na taxa de desemprego.

Entretanto, em 2008, o mundo sofreu uma crise, essa alavancada pelos Estados Unidos da América. Observou-se que o governo ágil imediatamente, em resposta à crise, e decretou a política anticíclica de redução do IPI no mercado automobilístico, o instrumento foi implementado em 2008 e utilizado pelo governo até janeiro de 2015. Ano o qual também ocorreu a modificação do acordo automotivo Brasil/México, e implantado o programa INOVAR-AUTO3. Ambas ações buscaram auxiliar a manutenção do crescimento da frota brasileira de automóveis novos.

Posto o cenário de aumento da demanda de automóveis via melhora socioeconômica da população, acrescido de incentivos ao consumo de automóveis dada a implementação política anticíclicas de desoneração de imposto, o presente trabalho tem por objetivo investigar qual foi o comportamento da demanda de automóveis nas microrregiões brasileiras e capitar os efeitos regionais utilizando a ponderação da demanda de automóveis na sua versão per capita.

O presente trabalho, analisará os efeitos regionais por meio do efeito de vizinhança, proporcionado pela interação espacial, controlando assim os efeitos das dependências espaciais e heterogeneidade espacial observável e não observável,

\footnotetext{
${ }^{3}$ O programa possui validade para o período de 2013 a 2017. O Programa estimula a concorrência e a busca de ganhos sistêmicos de eficiência e aumento de competitividade através de uma parceria entre Brasil e México (ALMEIDA FILHO, 2018).
} 
por meio do uso das metodologias Analise Exploratória de Dados Espaciais (AEDE), e Painel de Dados Espacial.

Ademais, por meio dos processos de convergência absoluta e condicional, esse trabalho também testará a hipótese da existência de clubes de convergência da demanda de automóveis, no período 2004 a 2015, além de investigar efeitos regionais da redução do IPI (Impostos sobre Produto Industrializado) com o objetivo de identificar se o consumo de automóveis por mil habitantes a nível de regional sofreu alteração no período de atuação dessa política (2008 a 2014), em relação ao período anterior (2004 a 2007).

Nesse contexto, o presente artigo tem como intuito contribuir em duas direções para a literatura sobre o desempenho da indústria automobilística. $O$ primeiro é uma motivação teórica para explicar os determinantes da demanda efetiva de automóveis, com foco especial no processo de convergência a nível Brasil. A segunda contribuição é uma aplicação empírica do método de painel de dados espacial e clubes de convergência, capaz de verificar a validade da proposição teórica para o Brasil. A melhor proxy para capturar a demanda efetiva de automóveis é a frota de automóveis, os automóveis licenciados em um país ou região em particular, é o número de automóveis utilizados diariamente, refletindo diretamente na capacidade de consumo dessa região ou pais.

Este artigo está estruturado em mais quatro seções, além desta, a segunda trata da proposição teórica da demanda de automóveis, bem como de uma investigação na literatura sobre o cenário econômico do país e mundo. Na terceira seção, apresentamos a abordagem empírica e o banco de dados utilizado. Os resultados encontrados e suas análises são realizados na quarta seção. Finalmente, a quinta seção apresenta as considerações finais.

\section{A Demanda Efetiva de Automóveis no Brasil}

A necessidade de locomoção urbana eficiente é de grande relevância para os grandes centros urbanos, pois uma cidade pode ser entendida como um sistema de interrelações entre espaços cheios e vazios, o que implica que seu planejamento interfere diretamente em seu funcionamento (COSTA et al., 2007; LIMA, 2005).

Ao passo que o transporte no Brasil é concentrado na malha rodoviária indicando o uso em grande monta de veículos automotores tanto no que diz respeito ao transporte urbano (quer seja coletivo ou individual) ou de carga (com uso de frotas de caminhões de todos os tipos) (RODRIGUES, 2008). 
Pires (2009) relata que o Brasil e o mundo durante o ano de 2008 experimentaram a crise financeira que por sua vez, predispõe diversas respostas de política econômica através de medidas anticíclicas, onde no Brasil uma importante ferramenta adotada pelo governo foi a de desoneração tributária resultando em aumento dos gastos públicos com o intuito de amenizar os efeitos da crise.

A exemplo de países como França, Alemanha, Inglaterra e EUA, o governo brasileiro adotou, em dezembro de 2008, políticas para incentivar a compra de automóveis novos visando assim a redução dos estoques desse setor que haviam aumentado expressivamente em virtude da queda da demanda, diferentemente dos países citados o incentivo brasileiro se deu por meio da desoneração temporária da alíquota de impostos indiretos como o imposto sobre produto industrializado (IPI) incidente sobre automóveis. Estas desonerações ocorreram entre os anos de 2008 a 2015. Sobre a desoneração de impostos do IPI no Brasil, os autores Lucinda (2017) e Costa Junior et al. (2018) afirmam que existiram efeitos positivos na demanda ao estimular novas vendas. No entanto, os autores ressaltam que as vendas de veículos durante o período cresceram a taxas decrescentes, pois segundo os mesmos, no mercado brasileiro as famílias apenas realizaram a antecipação do consumo.

Os resultados encontrados por Costa Junior et al., (2018) sugerem que o impacto de incentivos por meio da redução da tributação não é a forma mais adequada para estimular a atividade econômica. Em suma os resultados encontrados pelo autor são:

I) A redução da alíquota do IPI sobre bens duráveis não foi a política mais adequada para estimular a atividade econômica;

II) Com o impacto da desoneração desse imposto, o produto agregado recua para um valor abaixo do seu estado estacionário.

Assim como Mian e Sufi (2012), Costa Jr et al. (2018) analisam as políticas de incentivos à compra de veículos novos nos EUA e no Brasil, respectivamente. Ambos concluem que as medidas não tiveram efeito de longo prazo na venda de veículos.

Através da literatura especializada, diversos trabalhos evidenciam que o setor automobilístico brasileiro é, além de dinâmico, de suma importância para o país, em trabalhos de previsão de demanda os autores Mattos et al., (2015) e Caroline et al., (2016) ambos levam em consideração os efeitos das alterações nas alíquotas dos Impostos em Produtos Industrializados (IPI) sob a demanda efetiva de automóveis. 
Em relação ao setor automobilístico o IPI se demonstra com grande relevância, alguns trabalhos que 0 avaliam direta ou indiretamente (COSTA JUNIOR; FANTINATTI; TELES, 2018; FREITAS JUNIOR, 2019; IPEA/DIMAC, 2009; MARTINS, 2013; MATTOS et al., 2015; OSHIRO, 2014). Sendo assim o presente estudo se relaciona com uma literatura buscando tratar os efeitos do IPI nesse trabalho, através de dummies de controle, tratadas especificamente na seção metodologia.

Segundo Costa Jr et al. (2018), os incentivos governamentais financeiros também devem ser investigados, pois estes incentivos exercem efeitos positivos na demanda brasileira de automóveis, especialmente em vista da má distribuição de renda do país. Ademais, pode-se observar a importância do comportamento da taxa de crescimento da frota de veículos frente a taxa de crescimento do Produto Interno Bruno (PIB) a partir da análise da Figura 1.

Figura 1 - Taxa de Crescimento da Demanda Efetiva de Automóveis por mil habitantes e variação do Produto Interno Bruto (PIB).

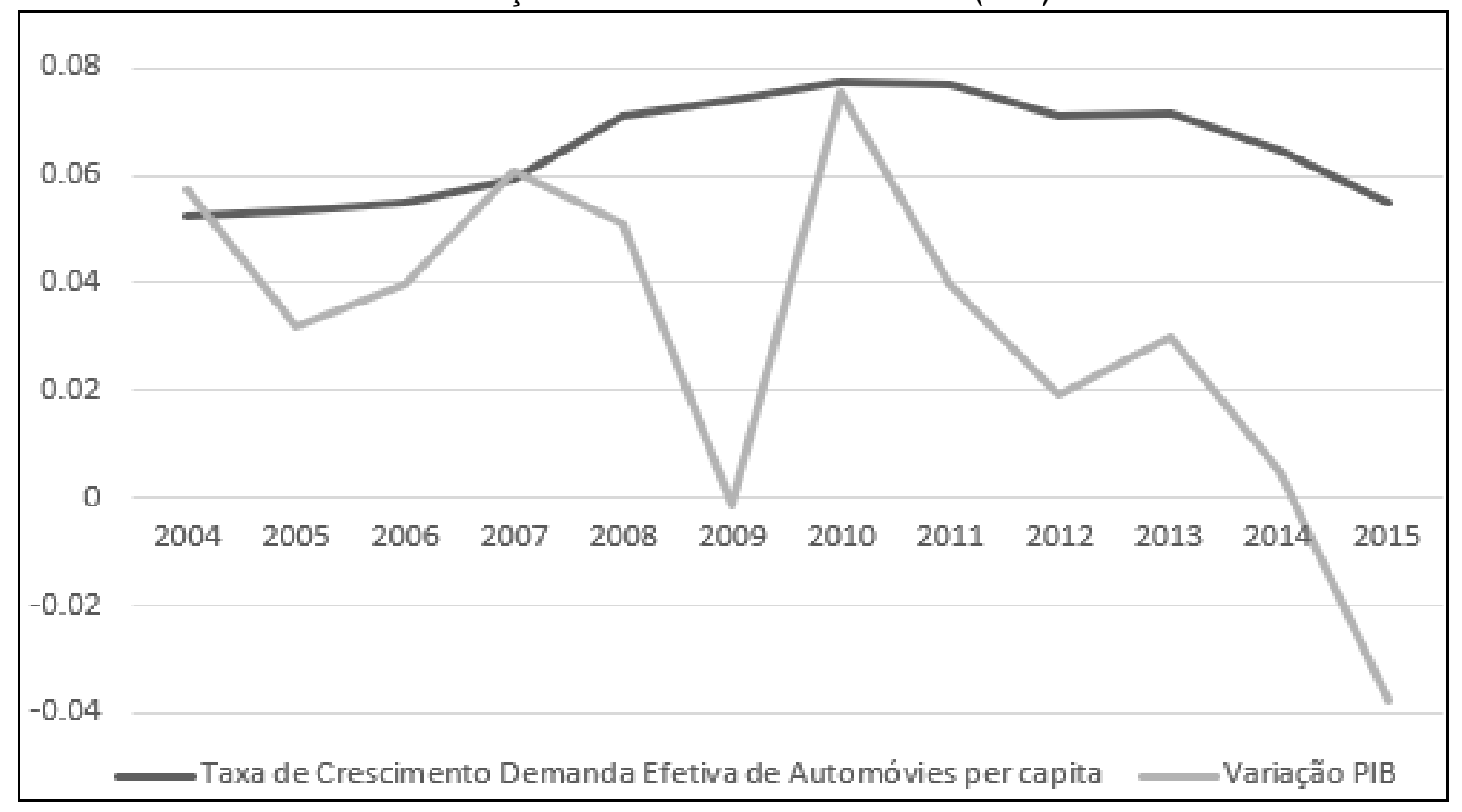

Fonte: IBGE E DENATRAN elaborado pelo autor.

É possível verificar que entre os anos de 2007 a 2009 ocorreu uma considerada redução da taxa de crescimento do PIB, fator possivelmente atrelado devido à crise estado unidense de 2008, bem como impactos posteriores da crise nos anos de 2012 até 2015. entretanto, ao observar a taxa de crescimento de venda de automóveis novos ponderados pela população infere-se que essa não sofreu grandes impactos, entretanto PIB do brasil apresentou uma redução significativa. 
Através da teoria econômica, esperasse que a queda no PIB, resulte imediatamente na queda no consumo, não obstante o presente trabalho buscará investigar os principais fatores para essa estabilidade no consumo de automóveis, os autores Lucinda (2017) e Costa (2018), em seus trabalhos discutem sobre as políticas anticíclicas, resposta à crise estado unidense de 2008.

Sobre a desoneração de impostos do IPI no Brasil, como política anticíclica os autores Lucinda (2017) e Costa Junior et al. (2018) afirmam que existiram efeitos positivos na demanda ao estimular novas vendas. No entanto, os autores ressaltam que as vendas de veículos durante o período cresceram a taxas decrescentes, pois segundo os mesmos, no mercado brasileiro as famílias apenas realizaram a antecipação do consumo.

O próximo capítulo, tem por objetivo, demonstrar as estratégias metodológicas utilizada no trabalho para obtenção dos resultados.

\section{Metodologia}

Em suma, observa-se que o automóvel, além de ser uma indústria importante economicamente para o Brasil, também pode ser considerado um transporte importante para a sociedade brasileira dada a fragilidade do transporte público.

No Quadro 1, apresenta-se as variáveis utilizadas no trabalho. Todas as variáveis foram logaritmizadas a fim de adquirir simetria entre si (ALMEIDA, 2012).

Quadro 1 - Variáveis explicativas utilizadas no trabalho.

\begin{tabular}{|l|l|c|}
\hline \multicolumn{1}{|c|}{ Variável } & \multicolumn{1}{|c|}{ Descrição } & Fonte \\
\hline Auto & Número de Automóveis per capita. & $\begin{array}{c}\text { DENATRAN e } \\
\text { IBGE }\end{array}$ \\
\hline Moto & Número de Motocicletas per capita. & $\begin{array}{c}\text { DENATRAN e } \\
\text { IBGE }\end{array}$ \\
\hline Onibus & Número de Ônibus per capita & $\begin{array}{c}\text { DENATRAN e } \\
\text { IBGE }\end{array}$ \\
\hline $\begin{array}{l}\text { Densidade } \\
\text { Populacional }\end{array}$ & $\begin{array}{l}\text { (Densidade Demográfica) Número de Habitantes por } \\
\text { km². }\end{array}$ & IBGE \\
\hline Pib & $\begin{array}{l}\text { Produto Interno Bruto por mil habitantes das } \\
\text { Microrregiões. }\end{array}$ & IBGE \\
\hline
\end{tabular}

Fonte: elaboração própria.

A variável dependente é a demanda efetiva de automóveis por mil habitantes que é composta a partir da fração dos automóveis pelos habitantes de uma microrregião. Os dados de automóveis foram obtidos através do Departamento Nacional de Trânsito (DENATRAN), os quais se utilizam de informações dos 
veículos a partir da microrregião de registro do automóvel. Em relação a população foram utilizados dados do Instituto Brasileiro de Geografia e Estatística (IBGE).

Do mesmo modo que a variável automóvel per capita, foram obtidas as variáveis: motocicleta por mil habitantes e ônibus per capita. A variável densidade populacional foi obtida pela fração de dois dados obtidos do IBGE, a primeira população e o segundo os quilômetros quadrados das microrregiões. Os dados condizentes ao Produto Interno Bruto (PIB) foram obtidos através do Sistema de Recuperação Automático (SIDRA) do IBGE e divididos pela população. Por fim, a densidade de emprego foi obtida através da $\operatorname{RAIS}^{4} \mathrm{e}$ a fração frente a população.

A partir da definição destes indicadores é possível elaborar a análise exploratória de dados espaciais como será discutida na próxima seção.

A análise exploratória de dados espaciais (AEDE) consiste num conjunto de técnicas utilizadas para identificar efeitos especiais, mais especificamente os de dependência e heterogeneidade espacial contidos na amostra. O primeiro efeito está relacionado inversamente à distância geográfica, enquanto o segundo, por outro lado, diz respeito às características próprias das unidades espaciais, que por sua natureza, podem diferenciar entre si.

Ambos, se identificados, devem ser devidamente controlados e tratados para evitar problemas no seu uso em modelos econométricos. Por isso, a AEDE é um instrumento valioso de auxílio no processo de especificação de modelos econométricos, pois, se a AEDE indicar que há algum tipo de processo espacial, esse deverá ser incorporado ao modelo ou tratado da forma correta evitando problemas como viés e inconsistência nos parâmetros.

Deste modo, a AEDE consegue captar padrões de associações espaciais (clusters espaciais), indicações de como os dados estão distribuídos, ocorrência de diferentes regimes espaciais ou outras formas de instabilidade espacial (não estacionariedade) e ainda identificar observações atípicas (outliers), conforme sugerido por ANSELIN (1995); PEROBELLI et al. (2007) e ALMEIDA (2012).

A dependência espacial significa que o valor de uma variável de interesse em uma região está relacionado no processo de dependência com o valor dessa mesma variável nas regiões vizinhas. Essa dependência ocorre em todas as direções, mas tende a diminuir seu impacto conforme se aumenta a distância geográfica. Por outro lado, a heterogeneidade espacial está relacionada com as particularidades das

\footnotetext{
${ }^{4}$ A (RAIS) é um relatório de informações socioeconômicas solicitado pelo Ministério do Trabalho e Emprego brasileiro às pessoas jurídicas e outros empregadores anualmente. Foi instituída pelo Decreto $n^{\circ}$ 76.900, de 23 de dezembro de 1975.
} 
regiões e pode causar instabilidade estrutural, ou seja, cada localidade pode ter uma resposta distinta em sua variável dependente se ocorrer alguma alteração na variável explicativa. A heterogeneidade induz um modelo econométrico a apresentar problema de heterocedasticidade o que torna as variâncias dos coeficientes com propriedades não assintóticas, inviabilizando os testes estatísticos realizados para verificar a consistência dos parâmetros e modelos (ALMEIDA, 2012).

No entanto, uma vez que o modelo apresenta tais problemas a forma sugerida por ALMEIDA (2012) para a sua resolução está na escolha da matriz de pesos espaciais discutidas na próxima seção.

O método utilizado para investigar os determinantes do crescimento da demanda por automóveis no Brasil será o de painel de dados espacial. Tal escolha é devido a demanda não estar, ao longo do período, relacionado simplesmente com os fatores explicitamente incluídos na regressão, mas também com características próprias de cada microrregião. O método de dados em painel possibilita justamente captar essa heterogeneidade dos elementos contidos na amostra que não pode ser identificada de forma direta e, portanto, irá compor o termo de erro, visando as estimativas quando correlacionadas com as variáveis explicativas.

Por isso, a estimação por um modelo clássico de regressão linear não é a melhor especificação, pois, nesses casos, há a quebra de uma das suas hipóteses básicas: a de ausência de autocorrelação entre as variáveis explicativas e o termo de erro. Isso pode tornar o modelo viesado e inconsistente. Dessa forma, a utilização da regressão com dados em painel tem como objetivo minimizar o viés e tornar o modelo consistente, ou seja, simétrico e com menor variância possível. Essa metodologia possibilita a melhor captura da dinâmica verdadeira apresentada pelo fenômeno por meio da identificação da heterogeneidade não observada.

Entretanto, um dos pressupostos do modelo de dados em painel é de que as unidades de corte transversal são independentes entre si. Segundo Almeida (2012) ao se investigar unidades espaciais como as microrregiões, há grande suscetibilidade da amostra apresentar autocorrelação espacial, especialmente ao se tratar de atividades que usualmente tendem a se concentrar nos grandes centros urbanos. No caso desse trabalho, pode-se observar que a demanda de automóveis tende a se concentrar em centros urbanos (CINTRA, 2014; HADDAD, 2015). Portanto, caso identificado a dependência espacial na análise exploratória de dados espaciais e confirmada a hipótese através do cálculo do I de Moram dos resíduos da 
regressão de painel com efeitos fixos, será incorporada na regressão por meio de um modelo espacial de dados em painel.

Para efeitos de comparação serão estimados os modelos espaciais por meio de efeito fixo (fixed effect - FE) e de efeito aleatório (random effect - RE). Posteriormente, o Teste de Hausman espacial será realizado para identificar qual modelo é o mais adequado para conjunto de dados. Por fim, critérios de informação de Akaike serão empregados para o verificar a qualidade do ajuste dos modelos considerando o melhor modelo, aquele que apresentar o menor valor do critério.

No presente trabalho serão estimados basicamente três modelos na tentativa de buscar o melhor ajuste. O primeiro modelo é o Spatial Error Model (SEM) que foca na autocorrelação espacial no termo de erro e pode ser descrito por

$$
\begin{aligned}
& y_{t}=X_{t} \beta+\mu+v_{t} \\
& v_{t}=\lambda M v_{t}+\epsilon_{t}
\end{aligned}
$$

Onde $M$ é a matriz de pesos espaciais que pode ser ou não igual a $W$, denotado a seguir, $\boldsymbol{W}$ como uma matriz de peso espacial $n \times n$; e para cada período $t=1, \ldots, T$, um vetor $n \times 1$ da variável dependente, $\boldsymbol{y}_{t}$, assim como $\boldsymbol{X}_{t}$ como uma matriz $n \times n$ de regressores.

O segundo modelo será o Spatial Autoregressive Model (SAR) expresso pela equação

$$
\boldsymbol{y}_{t}=\rho \boldsymbol{W} \boldsymbol{y}_{t}+\boldsymbol{X}_{t} \beta+\mu+\boldsymbol{\epsilon}_{t} \quad t=1, \ldots, T
$$

onde $\boldsymbol{\mu} \sim N\left(0, \sigma_{\mu}^{2}\right)$ se for efeitos aleatórios, enquanto $\boldsymbol{\mu}$ é um vetor de parâmetros a serem estimados na sua variante de efeitos fixos. As hipóteses padrões sobre o modelo SAR são que $\epsilon_{i t} \sim N\left(0, \sigma_{\varepsilon}^{2}\right)$ e $E\left(\epsilon_{i t} \epsilon_{j s}\right)=0$ para $i \neq j$ e/ou $t \neq s$.

Por fim, o Spatial Durbin Model que se caracteriza como uma generalização do modelo SAR com a adição de variáveis independentes defasadas espacialmente como variáveis explicativas descrito pela equação (9).

$$
\boldsymbol{y}_{t}=\rho \boldsymbol{W} \boldsymbol{y}_{t}+\boldsymbol{X}_{t} \beta+W Z_{t} \theta+\mu+\epsilon_{t}
$$


É possível que $\boldsymbol{Z}_{\boldsymbol{t}} \neq \boldsymbol{X}_{\boldsymbol{t}}$, assim a estimação dos referidos modelos adotarão o método de Máximo Verossimilhança, conforme Elhorst (2003). Não há estudo especifico sobre convergência da demanda efetiva de automóveis no Brasil. Logo as estratégias empíricas da metodologia usada, seguem a fundamentação da hipótese de convergência utilizadas em diversos trabalhos dos distintos temas como por exemplo; Agricultura (ALMEIDA, 2008); Crime (DE ALMEIDA, 2014); A Pecuária Bovina (FREITAS JR, 2018); Inovação (DE OLIVEIRA, 2016); Internet (CELBIS, 2018); Distribuição de Renda (LAURINI, ANDRADE E PEREIRA, 2003; GONDIM, 2004); Trabalhador Classe Criativa (MISHRA, 2016); Tecnologia (FREITAS, 2010); Preços de carros no mercado europeu (GOLDBERG, 2005), os autores utilizam o modelo de convergência sobre os temas propostos. No entanto, alguns autores identificaram a necessidade de aprimoramento dos modelos básicos de convergência absoluta e condicional, aprimoramentos estes se dão na criação de novas regiões de estudo, devido suas diferenças estruturais, este tratamento será realizado neste trabalho.

Conforme a metodologia proposta por Mankiw (1992) e Sala-I-Martin (1996) corroborada por Johnson e Takeyama (2003) e testada empiricamente por Coelho (2006), neste trabalho adotar-se-á estratégia para diferenciar empiricamente as hipóteses de convergência condicional e clubes convergência, ademais, utilizará a técnica de árvore de regressão com base no dendograma hierárquico para a determinação dos clubes de convergência.

Coelho (2006) analisou a hipótese de convergência para os municípios brasileiros entre 1970 e 2000, para o autor os municípios brasileiros são melhores descritos a partir da hipótese de convergência por clubes, ou seja, segundo o autor há evidencias da existência de zonas de atração e múltiplos estados estacionários que caracterizam a dinâmica da renda per capita, assim, as condições iniciais são realmente importantes para determinar a trajetória de renda dos municípios ao longo do tempo. Os resultados mostram também em concordância com os estudos acima, que há um componente regional na formação dos clubes de convergência.

De modo geral a maioria dos trabalhos sobre convergência pressupõe que as regiões de estudo são unidades geográficas isoladas, não considerando os efeitos espaciais (dependência e heterogeneidade) subjacentes (JOHNSON e TAKEYAMA, 2003). Como missão de investigar a análise de convergência da demanda de automóveis das microrregiões brasileiras, foi incorporado o efeito de vizinhança proporcionado pela interação espacial, e, portanto, controlando-se para os efeitos 
espaciais, dependência espacial e heterogeneidade espacial observável e não observável (MANKIW, 1992 e SALA-I-MARTIN, 1996). Para atingir o objetivo proposto, foi construído um modelo de convergência espacial absoluto, um condicional e dois de clubes para as 558 microrregiões brasileiras para o período anual entre 2004 e 2015.

Que seguirá os modelos de convergência, assim como presentes na literatura de crescimento econômicos, estes partem de diferentes abordagens acerca da convergência, em relação a convergência da renda e consequentemente, do crescimento econômico. Uma das mais utilizadas refere-se ao $\beta$-convergência (BAUMOL, 1986; BARRO; SALA-I-MARTIN, 1992). Nele, a convergência ocorre a partir das regiões que têm um menor poder aquisitivo apresentam crescimento num ritmo mais acelerado do que as regiões mais ricas, havendo uma relação negativa entre crescimento da renda por mil habitantes e o nível de renda por mil habitantes inicial.

A hipótese é que todas as regiões convergem para um único estado estacionário, independente das suas condições iniciais, denominado de convergência absoluta (5), conforme descrito especificamente para este trabalho, segue o modelo de convergência absoluta para o automóvel por mil habitantes das microrregiões brasileiras.

$$
\ln \left(\text { Auto }_{i, t} / \text { Auto o }_{i, t-1}\right)=\alpha+\beta \ln \left(\text { Auto }_{i, t-1}\right)+\varepsilon_{i, t}
$$

Em que: Auto é o número de automóveis por mil habitantes na microrregião i; $L n$ é o logaritmo; $t$ refere-se aos valores de 2004 até 2015 e $t-1$ abrange valores no período anterior; $\varepsilon_{i}$ é o termo de erro.

No entanto, autores, como Bertussi e Figueiredo (2009), inferem que as economias somente convergem para o mesmo estado estacionário se elas apresentarem características estruturais similares. Neste sentido, diferentes estados estacionários coexistem, tendo uma convergência condicional (6).

$$
\ln \left(\text { Auto }_{i, t} / \text { Auto }_{i, t-1}\right)=\alpha+\beta \ln \left(\text { Auto }_{i, t-1}\right)+\delta \ln \left(\text { Controle }_{i, t-1}\right)+\varepsilon_{i, t}
$$

Em que: Controle $e_{i, t-1}$ refere-se a um vetor de variáveis de controle (características estruturais) da microrregião $i$ no período inicial $(t-1)$. No presente trabalho, o vetor de controle é composto pelas variáveis: Motc e ônibus (proxy para opções de transporte), Densidade Pof (proxy para a escala urbana) e PIB (proxy 
poder de consumo) Todas essas variáveis foram defasadas temporalmente visando mensurar seu efeito subsequente na taxa crescimento da demanda efetiva de automóveis per capita.

O modelo (5) foi estimado utilizando a econometria espacial, que tem por objetivo tratar a dependência espacial. No que se refere o controle da heterogeneidade espacial, forma estimados os modelos de clube de convergência (6), que por sua vez delimitam geograficamente os modelos já estimados e serão abordados na seção dos resultados.

Quando o valor do modelo de convergência é obtido, é possível estimar a velocidade (teta) na qual essa convergência está ocorrendo, segundo Rey e Montoury (1999) por meio da seguinte expressão:

$$
\boldsymbol{\theta}=\frac{\operatorname{Ln}(\boldsymbol{\beta}+1)}{(-k)}
$$

Onde $\boldsymbol{\theta}$ é a velocidade de convergência; $\boldsymbol{\beta}$ é o coeficiente de convergência estimado e $\boldsymbol{k}$ é o número de anos em períodos de tempo de aposta. A meia-vida, por sua vez é calculada pela fórmula a seguir

$$
\boldsymbol{\tau}=\frac{\operatorname{Ln}(2)}{(\theta)}
$$

A meia vida $\boldsymbol{\tau}$ refere-se ao tempo necessário para que as microrregiões se desloquem a meio caminho entre seus respectivos estados estacionários.

Desse modo as aplicações da metodologia estão apresentadas na seção responsáveis pela análise descritiva e resultados tanto qualitativos quanto dos modelos econométricos estão apresentadas a seguir.

\section{Resultados}

Uma análise descritiva prévia dos dados foi realizada relativamente às frotas por mil habitantes de automóveis nas microrregiões aqui analisadas com a finalidade de verificar a dinâmica apresentada por essas demandas efetivas no Brasil (Figura 2). 
Figura 2 - Distribuição Brasileira da demanda de automóvel por 1000 habitantes nos anos ${ }^{5}$ de (a) 2006, (b)2009 e (c)2013

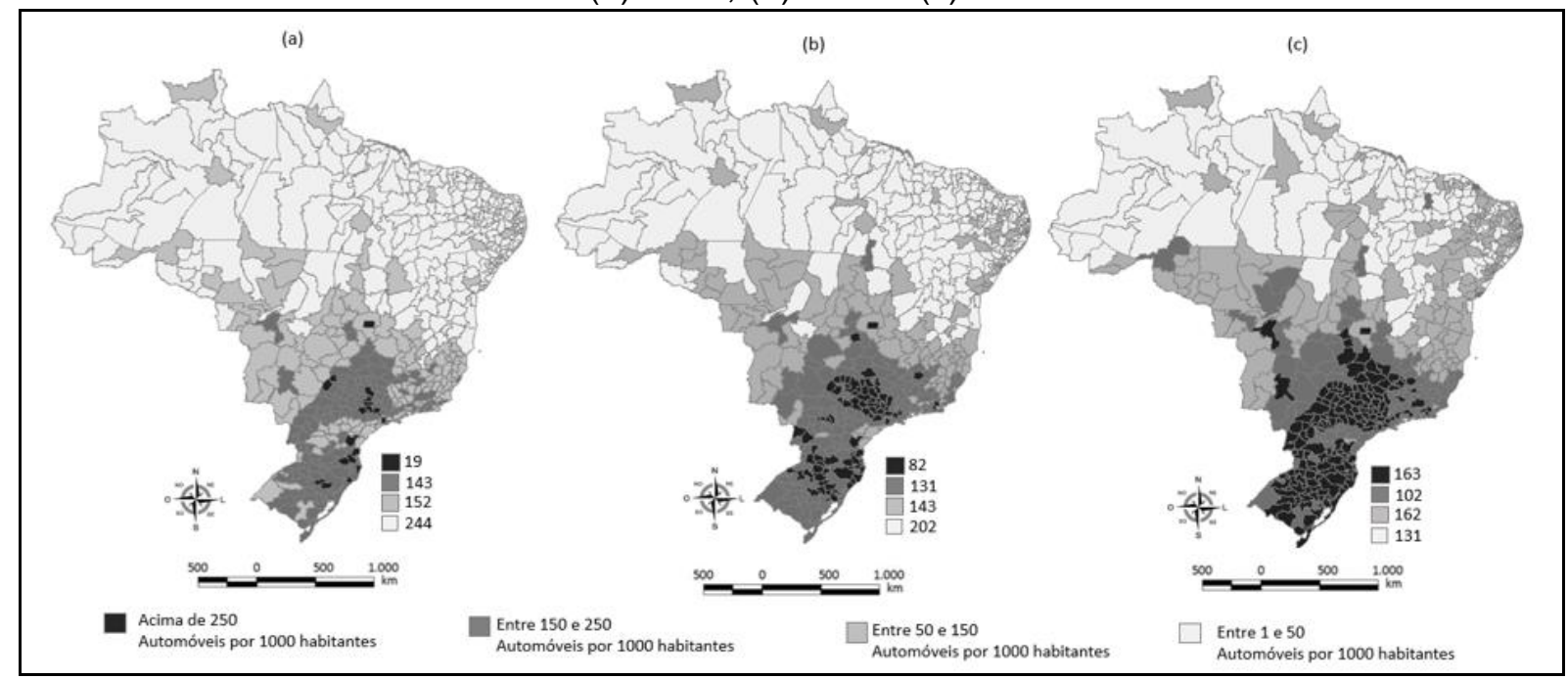

Fonte: Elaboração própria.

O objetivo da figura 2 é retratar os períodos, anterior e posteriores a implementação da exoneração de imposto sobre os automóveis é possível observar uma melhora geral no consumo de automóveis por mil habitantes no Brasil, dois efeitos podem ser percebidos uma de concentração de automóveis nas regiões sul, sudeste e centro oeste, além de uma melhora das condições das regiões norte e nordeste.

É possível assim observar um processo de autocorrelação espacial que pode ser testado através da Análise Espacial de Dados (AEDE) ${ }^{6}$.

Ademais, com o objetivo de entender o comportamento da taxa de crescimento da frota por mil habitantes e com finalidade adjacente de captar e revelar se há presença de autocorrelação espacial nos dados, computou-se, por meio do software GeoDa, a estatística I de Moran. Foram calculados os coeficientes por meio das matrizes de peso espacial (W) com a convenção de 3, 5, 7 e 10 vizinhos. A utilização de diversas convenções de cálculo para matriz de defasagem espacial (Anexo A) buscou identificar aquela que capta da melhor forma o processo de autocorrelação espacial presente nos dados. Isso é comprovado por meio dos coeficientes I de Moran, cujos valores apresentaram-se positivos e estatisticamente significativos independente da matriz de convenção aplicada.

\footnotetext{
5 (a) - período composto pelas médias dos anos de 2004, 2005, 2006 e 2007. (b) - período composto pelas médias dos anos de 2008, 2009, 2010 e 2011. (c) - período composto pelas médias dos anos de 2012, 2013, 2014.

${ }^{6}$ A AEDE fornece informações sobre a existência ou não da dependência espacial e da heterogeneidade espacial no fenômeno estudado, como apresentado na seção anterior.
} 
Portanto, no período considerado, microrregiões com taxa de crescimento e elevada número de automóveis por mil habitantes tendem a estar rodeadas também por regiões com altos valores (e vice-versa)., faz-se o uso da estatística LISA que se mostra apropriada para identificar agrupamentos espaciais significativos (Clusters), assim como instabilidade local da medida de associação global da estatística I de Moran, revelada com a presença de valores espaciais extremos. A hipótese nula da estatística LISA continua sendo a de ausência de associação espacial, embora passe agora a ser considerado o nível local e não mais o global (Figura 3).

Figura 3 - Mapa de significância local de Moran (LISA) para Taxa de Crescimento da Demanda de Automóveis por 1000 habitantes nos anos ${ }^{7}$ de 2005, 2009 e 2012.

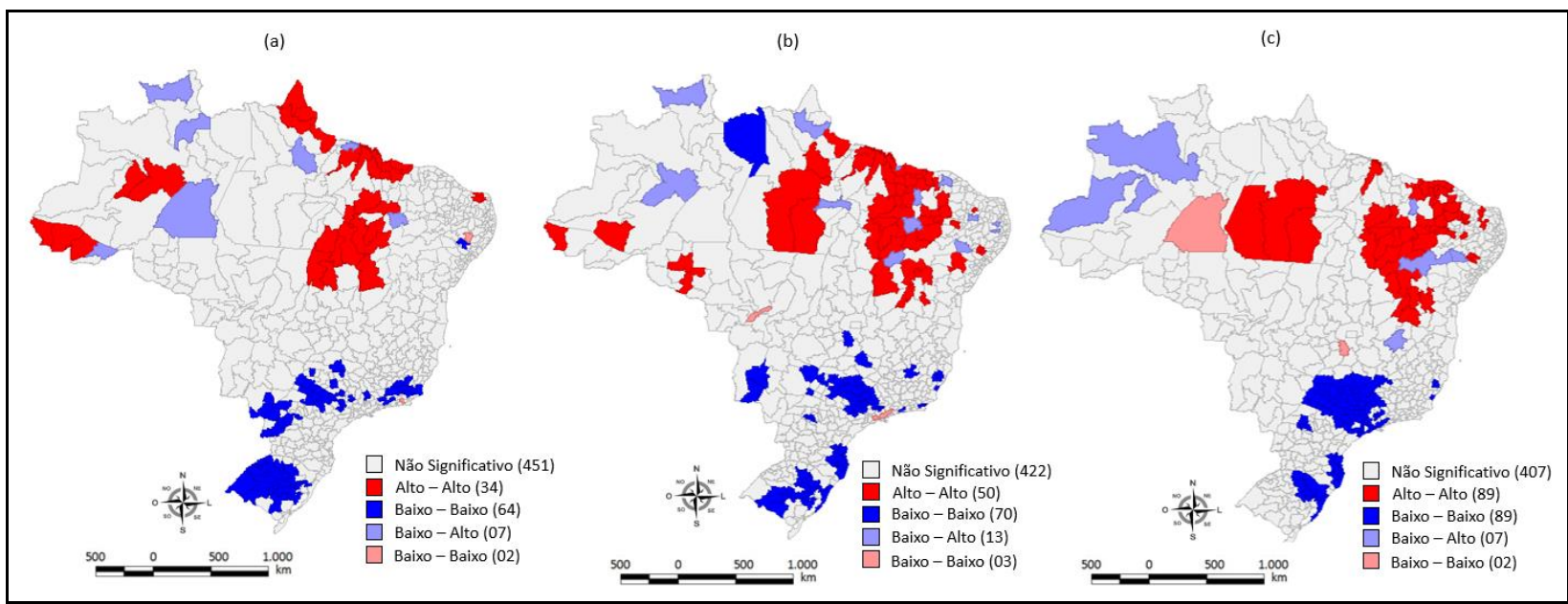

Fonte: Elaboração própria.

A partir da Figura 3 pode se observar os mapas de clusters (LISA) para taxa de crescimento da média de automóveis por mil habitantes nos períodos (a), (b) e (c), identificando os quatro tipos de associações espaciais possíveis, isto é, os padrões Alto-Alto (AA), Baixo-Baixo (BB), Alto-Baixo (AB) e Baixo-Alto (BA).

No período (a), 34 microrregiões do Brasil apareciam no cluster alto-alto, entretanto, no esse número aumentou para 50 e posteriormente para 89 nos periodos (b) e (c) respectivamente, ou seja, ocorreu um aumento das microrregiões com alto número por mil habitantes de automóveis no período considerado, de modo que mais microrregiões passaram a ter uma taxa de crescimento positiva da demanda de automóveis por mil habitantes.

\footnotetext{
${ }^{7}$ (a) - período composto pela taxa de crescimento do ano de 2004 a 2007. (b) - período composto pela taxa de crescimento do ano de 2008 a 2011. (c) - período composto pela taxa de crescimento do ano de 2012 a 2014.
} 
Ainda sobre o prisma das taxas de crescimento da frota de automóveis por mil habitantes no Brasil, destacam-se aglomerações de microrregiões com padrão espacial do tipo $A A$ é possível observar que há um processo de crescimento localizadas exclusivamente na região norte e nordeste, isso indica uma expansão da demanda nessa região. Tal dinâmica apresentada, entretanto, não é suficiente para tornar as regiões pertencentes ao padrão $A A$, este fator pode estar relacionado com o estoque inicial de automóveis por mil habitantes baixo em relação ao restante do Brasil, o que indica grande diferença estrutural entre as regiões (BAUMGARTEN, 1972).

O autor Rubim (2013) evidencia que a demanda de automóveis atrelados a distribuição de renda, sendo similar a formação demanda encontrada no trabalho.

Pode-se inferir, dessa forma, a ocorrência de um processo de transbordamento, dado a forte consolidação desse meio de transporte nas regiões Sul, Sudeste e Centro-Oeste. Por fim, nota-se que para todos os casos a influência positiva se manteve mais forte apenas para o vizinho mais próximo, diminuindo esse efeito conforme se aumenta o número de vizinhos da matriz de ponderação.

O método utilizado para investigar as motivações do crescimento demanda por mil habitantes brasileira de automóveis foi o de painel de dados espacial. Tal escolha se deve ao fato de que a demanda de automóveis ao longo do tempo pode não estar simplesmente relacionada com os fatores explicitamente incluídos na regressão, mas também com características próprias de cada microrregião.

O método de dados em painel possibilita justamente captar essa heterogeneidade dos elementos contidos na amostra que não pode ser identificada de forma direta e, portanto, acabaria sendo incluído no termo de erro, viesando as estimativas quando estão correlacionadas com as variáveis explicativas.

Por isso, a estimação por um modelo clássico de regressão linear não seria a melhor especificação pois nesses casos, há quebra de uma das suas hipóteses básicas: a de ausência de auto correlação entre as variáveis explicativas e o termo de erro. Isso pode tornar o modelo viesado e inconsciente. Dessa forma, a utilização da regressão com dados em painel tem como objetivo minimizar o viés e tornar o modelo consistente, ou seja, simétrico e com menor variância possível. Sendo assim, possibilitando a melhor captura da dinâmica verdadeira apresentada pelo fenômeno por meio da identificação da heterogeneidade não observada.

Como já discutido a demanda de automóveis têm importantes repercussões na estrutura econômica de um país, portanto diferentes autores como: Demaio 
(2009), De Azevedo Meiners (2011), Rubim (2013), Haddad (2015), De Moura Vogt (2017), defendem em seus estudos que há um impacto local na dinâmica econômica a partir dos estudos com a questão relacionadas ao automóvel. Este trabalho considera a nível agregado as relações entre o objeto de estudo o automóvel com variáveis socioeconômicas contidas no espaço e buscará testar empiricamente a possibilidade de a questão espacial ser relevante para o estudo do objeto.

Neste momento é importante é a escolha da matriz mais adequada, esta por sua vez deve respeitar certas propriedades desejáveis e certas particularidades do estudo em questão. Segundo Almeida (2012), a sugestão da escolha da matriz a ser usada deve vir, das características do fenômeno em estudo. Baumont (2004), busca escolher uma matriz $W$ que capte a maior parte da dependência espacial dos resíduos através do teste de diagnóstico de Baumont:

a) Estima-se o modelo clássico de regressão linear,

b) Testam-se os resíduos desse modelo para autocorrelação espacial, usando o I de Moran para um conjunto de matrizes W;

c) Seleciona-se a matriz de pesos espaciais que tenha gerado o mais alto valor de Moran e que seja significativo estatisticamente. Conforme pode ser observado no Apêndice $B$, as matrizes utilizadas foram: Matriz de 3 vizinhos para o modelo Brasil absoluto e condicional, o clube de convergência norte seguiu a mesma matriz do Brasil, matriz de 3 vizinhos e por fim, o clube de convergência sul por sua vez apresentou a os maiores I de Moran residuais de acordo com a matriz rainha de primeira ordem.

No que se refere aos problemas econométricos, foi identificada a presença de heterocedasticidade por meio do teste de Wald que apresentou um valor de 856,52, rejeitando a hipótese nula de variância constante nos resíduos. Dessa forma, todos os modelos espaciais foram estimados usando o erro padrão robusto Disccoll-Kraay, com a finalidade de controlar o problema.

Para a escolha entre o modelo de efeito fixo ou efeito aleatório, utilizou-se do teste de Hausman, sendo que houve rejeição da hipótese nula de que não há diferença sistemática entre os coeficientes estimados ${ }^{8}$. Portanto, a estimação por efeito fixo se mostrou a mais indicada para estimação dos modelos espaciais de dados em painel. Posteriormente, buscou-se definir qual modelo espacial é aquele que melhor representa e capta a dinâmica do fenômeno em estudo.

\footnotetext{
${ }^{8}$ Estatística Chi ${ }^{2}$ para o modelo Brasil condicional: 252.71; norte condicional: 98.42 ; Sul condicional:
} 542.23 . 
Utilizando-se o critério de informação de Akaike, verifica-se que o modelo de Durbin Espacial (SDM) foi aquele que apresentou o menor valor para esse critério de ajuste, tornando-se, dessa forma, o modelo escolhido. Portanto, as análises posteriores serão realizadas tendo como referência o modelo SDM, ressaltando que as demais estimativas foram apresentadas visando demonstrar a robustez dos coeficientes para os modelos espaciais estimados com a técnica de dados em painel.

O fato do modelo de Durbin Espacial (SDM) ser o escolhido, confirma a importância de incorporar os spillovers de variáveis independentes para explicar a taxa de crescimento da demanda efetiva per capita. Como por exemplo a as evidências encontradas pelos autores Pereira (1998); Souza (2010), Bertucci (2011), Lotufo (2011), HADDAD (2015) que por sua vez trazem em seus estudos, a importância da demanda de automóveis na dinâmica econômica de uma determinada região.

$\mathrm{Na}$ Tabela 1, tem-se os resultados relacionados às estimativas dos modelos globais, visando identificar a existência de convergência (absoluta) das microrregiões do Brasil entre o período de 2004 até 2015.

Tabela 1 - Resultados econométricos da convergência absoluta da taxa de crescimento da demanda de automóveis por mil habitantes nas microrregiões brasileiras de 2004 a $2015^{9}$.

\begin{tabular}{|c|c|c|c|c|}
\hline \multirow{2}{*}{ Variáveis } & \multicolumn{4}{|c|}{ Modelos } \\
\hline & Efeito Fixo (I) & SEM (II) & SAR (III) & SDM (IV) \\
\hline Auto $(\omega)_{t-1}$ & $\begin{array}{c}-0.0253^{* * *} \\
(0.000)\end{array}$ & $\begin{array}{c}-0.0543^{* * *} \\
(0.018)\end{array}$ & $\begin{array}{c}-0.0435^{\star * *} \\
(0.0140)\end{array}$ & $\begin{array}{c}-0.0913^{\star \star \star} \\
(0.004)\end{array}$ \\
\hline WAuto $(\omega)_{t-1}$ & - & - & - & $\begin{array}{c}0.0737^{\star \star *} \\
(0.005)\end{array}$ \\
\hline$\lambda$ & - & $\begin{array}{l}0.2077 \\
(0.128)\end{array}$ & - & - \\
\hline$\rho$ & - & - & $\begin{array}{c}0.1595^{\star * *} \\
(0.126)\end{array}$ & $\begin{array}{c}0.1866^{\star \star \star} \\
(0.019)\end{array}$ \\
\hline Constante & $0.0162^{\star \star *}(0.002)$ & $0.0085^{\star *}(0.003)$ & $\begin{array}{c}0.0086^{* * *} \\
(0.003)\end{array}$ & $\begin{array}{c}0.0084^{\star \star *} \\
(0.000)\end{array}$ \\
\hline $\begin{array}{c}\text { Crit. informação } \\
\text { Akaike }\end{array}$ & -12378.86 & -12809.27 & -12768.14 & -12911.81 \\
\hline № de obs. & 6.696 & 6.696 & 6.696 & 6.696 \\
\hline
\end{tabular}

Nota: ${ }^{* * *}$ Significante ao nível de $1 \%$; ** Significante ao nível de $5 \%$, *Significante ao nível de $10 \%$. Fonte: Resultado da pesquisa.

Os resultados das estimações apontam que há um processo de homogeneização da demanda de automóveis entre as microrregiões brasileiras, fato

\footnotetext{
${ }^{9}$ No que consiste ao modelo de convergência brasil absoluto, segundo Almeida (2012), a oscilação encontrada no beta ( $\beta$ ) convergência para os modelos SEM(II) SAR(III) e SDM(IV) apresentados na tabela 5, podem ser devidos problema de omissão de variável relevante e/ou heterogeneidade na amostra.
} 
captado pelo sinal negativo da variável Auto $(\omega)_{t-1}$ que apresentou significância estatística ao nível de 1\%. Isso indica que microrregiões com grande demanda efetiva por mil habitantes apresentaram uma taxa de crescimento inferior do que aquelas localidades com baixa demanda efetiva.

Portanto, para o período considerado de 2004 a 2015 houve um processo de avanço da taxa de crescimento da demanda efetiva por mil habitantes de automóveis em microrregiões que, anteriormente, possuíam uma frota por mil habitantes relativamente menor (BETUCCI, 2011; DENATRAN, 2018).

Desta forma, identificou-se também que a taxa de crescimento da demanda efetiva por mil habitantes de uma determinada microrregião tem o potencial de gerar transbordamentos positivos na dinâmica de crescimento de seus vizinhos próximos, fato captado pelo coeficiente espacial $\rho$ que se mostrou significativo e positivo ao nível de 1\%. Pode-se observar que medida em que os aglomerados econômicos passam a se desenvolver as cidades se tornam mais verticais, ou seja, há uma expansão da área, a partir da expansão das cidades, surge uma maior necessidade de transporte, através da expulsão das classes sociais vulneráveis para as zonas periféricas das cidades, ou pela criação do efeito conurbação ${ }^{10}$, acarretado pelo crescimento das cidades (HADDAD, 2015; MACHADO, 2017; MARICATO, 2017).

Conforme destacado na análise espacial (LISA) na Figura 3 a existência de externalidades espaciais positivas torna a necessidade da mobilidade mais dinâmica, isto é, as economias pertencentes as estas regiões geram spillovers positivos, o que induz ao aumento da demanda de transporte ao longo do espaço ocasionando a formação de clusters espaciais de alta demanda de automóveis per capita.

Referente a matriz espacial de ponderação escolhida para o modelo Brasil Condicional foi adotada a estratégia de determinação da matriz de defasagem via escolha da matriz que gerasse o maior coeficiente I de Moran para os resíduos da regressão Painel de Efeito Fixo (I), como pode ser observado no (Apêndice B), optou-se pela escolha da matriz de 3 vizinhos (K3), pois a mesma apresentou-se com maior I de Moran dos resíduos para 7 anos dos 12 anos considerados na análise.

$\mathrm{Na}$ Tabela 2, apresentam-se os resultados da estimação para a convergência condicional dos determinantes da taxa de crescimento da demanda de automóveis

${ }^{10}$ A conurbação é um fenômeno urbano, dado pela junção de duas ou mais cidades que se desenvolvem umas próximas a outras, de tal forma que acabam se unindo como se fosse apenas uma. 
per capita. A correlação das variáveis explicativas pode ser observada mais detalhadamente no Apêndice $A^{11}$.

Tabela 2 - Convergência condicional dos determinantes da taxa de crescimento da demanda de automóveis por mil habitantes no Brasil no período de 2004 a $2015^{12}$.

\begin{tabular}{|c|c|c|c|c|}
\hline \multirow{2}{*}{ VARIÁVEIS } & \multicolumn{4}{|c|}{ Painel Espacial ${ }^{13}$} \\
\hline & Efeito Fixo (I) & SEM (II) & SAR (III) & SDM (IV) \\
\hline Auto $_{\mathrm{t}}$ & $\begin{array}{c}-0.0355^{\star \star *} \\
(0.0019)\end{array}$ & $\begin{array}{c}-0.1041^{* * *} \\
(0.0051)\end{array}$ & $\begin{array}{c}-0.1029^{* * *} \\
(0.0050)\end{array}$ & $\begin{array}{c}-0.1197^{* * *} \\
(0.0052)\end{array}$ \\
\hline Moto $_{t}$ & $\begin{array}{c}0.0069^{* * *} \\
(0.0016)\end{array}$ & $\begin{array}{c}0.0061 \\
(0.0037)\end{array}$ & $\begin{array}{c}0.0070^{* * *} \\
(0.0035)\end{array}$ & $\begin{array}{c}-0.0450^{* * *} \\
(0.0052)\end{array}$ \\
\hline Onibus $_{t}$ & $\begin{array}{c}0.0002 \\
(0.0012)\end{array}$ & $\begin{array}{c}0.0006 \\
(0.0021)\end{array}$ & $\begin{array}{c}0.0005 \\
(0.0020)\end{array}$ & $\begin{array}{c}0.0208^{* \star *} \\
(0.0027)\end{array}$ \\
\hline Densidade popt & $\begin{array}{c}0.0115^{\star * *} \\
(0.0024)\end{array}$ & $\begin{array}{c}0.2724^{* * *} \\
(0.0412)\end{array}$ & $\begin{array}{c}0.2535^{\star * *} \\
(0.0393)\end{array}$ & $\begin{array}{c}0.2845^{* * *} \\
(0.0453)\end{array}$ \\
\hline Densidade pop $_{t}^{2}$ & $\begin{array}{c}-0.0013^{* \star *} \\
(0.0003)\end{array}$ & $\begin{array}{c}-0.0225^{\star * *} \\
(0.0060)\end{array}$ & $\begin{array}{c}-0.0208^{* * *} \\
(0.0057)\end{array}$ & $\begin{array}{c}-0.0360^{* \star *} \\
(0.0069)\end{array}$ \\
\hline$P i b_{t}$ & $\begin{array}{c}0.0550^{* * *} \\
(0.0080)\end{array}$ & $\begin{array}{c}0.1348^{\star \star *} \\
(0.0125)\end{array}$ & $\begin{array}{c}0.1333^{* * *} \\
(0.0118)\end{array}$ & $\begin{array}{c}0.0889^{* * *} \\
(0.0198)\end{array}$ \\
\hline$P i b_{t}^{2}$ & $\begin{array}{c}-0.0099^{\star * \star} \\
(0.0015)\end{array}$ & $\begin{array}{l}-0.0205 \\
(0.0022)\end{array}$ & $\begin{array}{c}-0.0200^{* * *} \\
(0.0021)\end{array}$ & $\begin{array}{c}-0.0146^{\star \star \star} \\
(0.0031)\end{array}$ \\
\hline W Auto ${ }_{t}$ & - & - & - & $\begin{array}{l}0.0228^{* *} \\
(0.0100)\end{array}$ \\
\hline W Moto $_{\mathrm{t}}$ & - & - & - & $\begin{array}{c}0.0542^{* \star *} \\
(0.0065)\end{array}$ \\
\hline W Onibus & - & - & - & $\begin{array}{c}-0.0237^{* * *} \\
(0.0037)\end{array}$ \\
\hline W Densidade popt & - & - & - & $\begin{array}{c}-0.1687^{* \star *} \\
(0.0631)\end{array}$ \\
\hline$W$ Densidade $\operatorname{pop}_{t}^{2}$ & - & - & - & $\begin{array}{l}0.0203^{* *} \\
(0.0093)\end{array}$ \\
\hline$W P i b_{t}$ & - & - & - & $\begin{array}{l}0.0592^{* *} \\
(0.0245)\end{array}$ \\
\hline$W P i b^{2}{ }_{t}$ & - & - & - & $\begin{array}{c}-0.0079^{* *} \\
(0.0038)\end{array}$ \\
\hline$\lambda$ & - & $\begin{array}{c}0.1381^{* * *} \\
(0.0168)\end{array}$ & - & 1 \\
\hline$\rho$ & - & & $\begin{array}{c}0.1376^{* * *} \\
(0.0161)\end{array}$ & $\begin{array}{c}0.1408^{* * *} \\
(0.0164)\end{array}$ \\
\hline
\end{tabular}

\footnotetext{
11 O coeficiente de correlação (neste caso, o de Pearson) indica uma relação linear relativamente forte e positiva entre as duas variáveis, foi observado uma alta correlação de 0,83 entre as variáveis Ln_Densidade_Populacional e Ln_Densidade_Emprego, por este motivo a última variável não foi usada no modelo, afim de não causar problemas estatísticos como inflar a variância, porém, vale justificar que sua retirada não afeta negativamente o modelo, uma vez que tem alta correlação com a variável Ln_Densidade_Populacional.

12 Houve controle da omissão de variável relevante, mas ainda continuou com coeficientes "instáveis", isso é sinal de heterogeneidade espacial na amostra (ALMEIDA, 2012). Por isso é necessário considerar a existência de clubes de convergência.

${ }^{13}$ Para verificar o comportamento da taxa de crescimento da demanda de automóveis per capita, foi adotado um procedimento metodológico proposto por Wooldridge (2002). Esse se caracteriza como uma forma de se incluir variáveis dicotômicas no contexto de dados em painel. Primeiramente, criouse uma variável temporal $(t)$ para todos os períodos analisados que assume 1 para a microrregião pertencente ao período e 0 para as demais. Por fim, estabeleceu-se uma dummy de interação temporal, resultando, portanto, em uma variável dicotômica para cada período analisado, menos um, evitando armadilha das variáveis dicotômicas.
} 
Nota: ${ }^{* \star *}$ Significante ao nível de $1 \%$; ${ }^{*}$ Significante ao nível de $5 \%$, ${ }^{*}$ Significante ao nível de $10 \%$. Fonte: Resultado da pesquisa.

Os resultados encontrados mostram que o modelo painel espacial condicional SDM se ajustou melhor aos dados comparativamente ao modelo de coeficientes globais. Essa conclusão se deve ao fato de que o modelo Brasil Condicional conforme Tabela 6 apresentou um menor critério de informação Akaike (AIC Brasil Condicional SDM $=-13269.36$ contra o AIC Brasil Absoluto SDM $=-12911.81$ ) apresentados na Tabela 1, estes resultados corroboram com os argumentos de Johnson e Takeyama (2003) quando há rejeição da hipótese de convergência $\beta$ absoluta, quais sejam a hipótese de convergência $\beta$ condicional ${ }^{14}$ ou a de convergência clube, ambas implicam a existência de um diferencial permanente inicial analisado captado pelas variáveis incluídas no modelo. Ademais, pode-se apontar que a existência de heterogeneidade espacial para a demanda de automóveis nas microrregiões brasileiras, seja ela por cada clube pertence a uma zona de atração determinada por suas condições iniciais.

Os resultados para $\circ \beta$ convergência para $\circ$ modelo Brasil Condicional seguem os encontrados no modelo Brasil Absoluto, assim é possível inferir a existência de um processo de convergência da demanda de automóveis, de modo que, aquelas microrregiões que tinham um baixo nível de demanda efetiva por mil habitantes inicial tenderam a ter, na média, uma taxa de crescimento subsequente maior. Está é uma importante evidência que responde de forma positiva a hipótese básica desse trabalho sobre o processo de homogeneização da demanda efetiva por mil habitantes de automóveis.

Este processo de homogeneização está de acordo com o aumento da demanda de automóvel seja por incentivo de políticas públicas ou ascensão social da população (HADDAD, 2015; DE MOURA VOGT, 2017; LUCINDA, 2017, COSTA JR 2018; VASCONCELOS, 2017).

Assim, os determinantes deste processo são analisados a seguir.

Moto: a variável demanda por motocicleta por mil habitantes ( Moto $_{t}$ ) apresentou um sinal negativo e significativo a $1 \%$ de modo que, aquelas microrregiões que tinham crescimento de demanda efetiva de automóvel por mil habitantes tenderam a ter, na média, uma redução na demanda de motocicleta per

\footnotetext{
${ }^{14}$ A convergência condicional implica a existência de diferenças estruturais dissemelhantes, que resulta em taxas de crescimento diferentes (MANKIW, 1992; SALA-I-MARTIN, 1996).
} 
capita. Assim, está ocorrendo um processo de substituição da motocicleta por automóveis.

Ônibus: por outro lado, a variável demanda efetiva por ônibus por mil habitantes (Onibus $s_{t}$ ), também se apresentou significativa ao nível de 1\%, sofreu um processo inverso da motocicleta, segundo o modelo é possível observar que na medida que a microrregião apresenta crescimento da demanda de automóveis, há consequentemente um aumento da frota por mil habitantes de ônibus.

Densidade habitacional: um importante determinante da demanda de automóveis no Brasil é a densidade populacional na forma linear e quadrática. Ambas foram significativas no nível de 1\% e com sinais esperados, ou seja, com positivo e negativo, respectivamente. Essa relação confirma para o Brasil as hipóteses de Jacobs (1969), Krugman (1991) e Griliches (1992) sobre a importância das economias de aglomeração e urbanização. Portanto, o aumento do número de pessoas em uma determinada localidade do país é capaz de acentuar a capacidade econômica entre os agentes, fatores capazes de aumentar os retornos do econômicos produzido, devido ao positivo (jacobiano externalidades.

No entanto, como indica o sinal negativo da versão quadrada da Densidade Populacional, esses benefícios de aglomeração ocorrem até uma certa escala urbana, a partir da qual passam a atuar como inibidores de efeitos econômicos, como citado por Cintra, (2014).

Também encontraram resultado semelhante para o Brasil. Portanto, este trabalho corrobora a importância das externalidades das economias de aglomeração jacobianas para explicar o processo da demanda efetiva de automóveis nas microrregiões brasileiras. Ademais, essa variável foi aquela que apresentou a maior magnitude entre as variáveis significativa, evidenciando sua importância relativa para o objeto de estudo nas microrregiões brasileiras.

PIB: em relação a variável explicativa PIB per capita, ambos os coeficientes apresentam significância estatística de 1\%, prevalecendo a hipótese do kuznets invertido, onde, a demanda de automóveis cresce em microrregiões onde o há um crescimento do PIB per capita, porém em regiões com alto PIB por mil habitantes há uma redução da demanda de automóveis. Este resultado corrobora com os estudos de; Rubim (2013), Cintra (2014), Haddad (2015), Lucinda, (2017).

Espaço (rho): a variável espaço rho $(\rho)$ de uma determinada microrregião tem o potencial de gerar transbordamentos espaciais positivos na dinâmica de 
crescimento de seus vizinhos próximos, fato captado pelo coeficiente espacial $\rho$ que se mostrou significativo ao nível de $1 \%$.

Variáveis defasadas: no que se refere as variáveis estruturais defasadas espacialmente, o automóvel defasado $\left(W\right.$ Auto $\left._{t}\right)$ e a motocicleta defasada espacialmente (W Moto $_{t}$ ) apresentaram sinal positivo e significância de 1\%, por conseguinte há um processo de spillover entre as microrregiões vizinhas que acompanha o movimento da taxa de crescimento da demanda efetiva por mil habitantes de automóveis.

As variáveis defasadas no espaço ( $W$ Onibus $\left._{t}\right)$ e (W Densidade hab $\left.b_{t}\right)$ apresentaram sinal negativo e significância de 1\%, indicando um transbordamento negativo dessa variável para a taxa de crescimento da demanda de automóveis por mil habitantes das microrregiões vizinhas. Portanto, quando há um aumento tanto de ônibus ou da densidade populacional de uma determinada região, as suas vizinhas próximas sofrem uma influência negativa em suas respectivas taxas de crescimento. Entretanto, quando considerado a variável densidade habitacional ao quadrado ( $W$ Densidade $h a b^{2}{ }_{t}$ ), observa-se um sinal positivo significante a $5 \%$, evidenciando um transbordamento oposto.

A variável PIB por mil habitantes $\left(W \mathrm{Pib}_{t}\right)$ e PIB por mil habitantes ao quadrado $\left(W \mathrm{Pib}^{2}{ }_{t}\right.$ ) expressa significância estatística de $5 \%$ e sinal semelhante as variáveis não defasadas espacialmente. O presente trabalho também buscou verificar se existem clubes de convergência, ou seja, encontrar e testar a existência de diferentes zonas de atração no Brasil, que são determinadas por suas condições iniciais. Sendo assim, cada zona de atração é caracterizada por um estado estacionário único para o qual todos os membros convergem no longo prazo.

De modo geral o trabalho buscou acrescentar conteúdo para a discussão acerca da literatura empírica sobre convergência, especificamente ao diferenciar convergência condicional e convergência clube. De acordo com a investigação qualitativa, especialmente por meio do método de Indicadores Locais da Associação Espacial (LISA), observou-se a existência de dois padrões espaciais bem definidos no Brasil. O primeiro composto por microrregiões do norte e nordeste atribuído a clusters baixo-baixo, em contrapartida a região sul e sudeste composto por microrregiões de alto-alto (Figura 3), após examinar isoladamente a taxa de crescimento (Tabela 3 ), observou-se que dois clusters foram formados, admitindo-se assim um importante contraste entre a frota por mil habitantes na dinâmica de sua taxa de crescimento. 
A alternativa para esta situação foi averiguar a adequação de clubes de convergências no Brasil, o recorte ad doc abrange a criação de dois clubes: o primeiro formado pelas regiões norte e nordeste chamado de Clube de Convergência Norte observado através da Tabela 3.

Tabela 3 - O comportamento da taxa de crescimento da demanda de automóveis nas regiões Norte e Nordeste do Brasil, 2004 a 2015.

\begin{tabular}{|c|c|c|c|c|}
\hline \multirow{2}{*}{ VARIABLES } & \multicolumn{4}{|c|}{ Painel Espacial ${ }^{15}$} \\
\hline & Efeito Fixo (I) & SEM (II) & SAR (III) & SDM (IV) \\
\hline Auto $(\omega)_{t-1}$ & $\begin{array}{c}-0.0431^{* * *} \\
(0.004)\end{array}$ & $\begin{array}{c}-0.1144^{* * *} \\
(0.007)\end{array}$ & $\begin{array}{c}-0.1134^{\star \star \star} \\
(0.007)\end{array}$ & $\begin{array}{c}-0.1196^{* \star \star} \\
(0.007)\end{array}$ \\
\hline Moto $(\rho)_{t}$ & $\begin{array}{c}-0.0015 \\
(0.004)\end{array}$ & $\begin{array}{c}-0.0707^{* * *} \\
(0.008)\end{array}$ & $\begin{array}{c}-0.0700^{* \star *} \\
(0.008)\end{array}$ & $\begin{array}{c}-0.0705^{\star * \star} \\
(0.008)\end{array}$ \\
\hline Onibus $(\rho)_{t}$ & $\begin{array}{c}0.0109^{\star \star \star} \\
(0.002)\end{array}$ & $\begin{array}{c}0.0223^{* * *} \\
(0.004)\end{array}$ & $\begin{array}{c}0.0219^{* \star *} \\
(0.004)\end{array}$ & $\begin{array}{c}0.0232^{* * *} \\
(0.004)\end{array}$ \\
\hline Densidade popt & $\begin{array}{c}0.0187^{\star \star *} \\
(0.004)\end{array}$ & $\begin{array}{c}0.2060^{* * *} \\
(0.069)\end{array}$ & $\begin{array}{c}0.1947^{* * *} \\
(0.067)\end{array}$ & $\begin{array}{c}0.3323^{\star * *} \\
(0.077)\end{array}$ \\
\hline Densidade pop ${ }_{t}^{2}$ & $\begin{array}{c}-0.0025^{\star * *} \\
(0.000)\end{array}$ & $\begin{array}{c}-0.0252^{* *} \\
(0.011)\end{array}$ & $\begin{array}{c}-0.0235^{\star *} \\
(0.011)\end{array}$ & $\begin{array}{c}-0.0454^{* * *} \\
(0.013)\end{array}$ \\
\hline$P i b_{t}$ & $\begin{array}{c}0.0547^{\star * \star} \\
(0.019)\end{array}$ & $\begin{array}{c}0.1140^{* * *} \\
(0.034)\end{array}$ & $\begin{array}{c}0.1169^{* * *} \\
(0.033)\end{array}$ & $\begin{array}{c}0.0746^{\star *} \\
(0.037)\end{array}$ \\
\hline$P i b_{t}^{2}$ & $\begin{array}{l}-0.0102^{* *} \\
(0.004)\end{array}$ & $\begin{array}{c}-0.0248^{* * *} \\
(0.006)\end{array}$ & $\begin{array}{c}-0.0252^{* * *} \\
(0.005)\end{array}$ & $\begin{array}{c}-0.0157^{* * *} \\
(0.006)\end{array}$ \\
\hline$W$ Auto $(\omega)_{t-1}$ & - & - & - & $\begin{array}{c}0.0358^{\star \star *} \\
(0.016)\end{array}$ \\
\hline$W$ Moto $(\rho)_{t}$ & - & - & - & $\begin{array}{l}0.0070 \\
(0.017)\end{array}$ \\
\hline W Onibus $(\rho)_{t}$ & - & - & - & $\begin{array}{c}-0.0138^{*} \\
(0.008)\end{array}$ \\
\hline W Densidade popt & - & - & - & $\begin{array}{c}-0.3297^{* * *} \\
(0.114)\end{array}$ \\
\hline$W$ Densidade pop $_{t}^{2}$ & - & - & - & $\begin{array}{c}0.0409^{* *} \\
(0.018)\end{array}$ \\
\hline$W P i b_{t}$ & - & - & - & $\begin{array}{l}0.0792 \\
(0.056)\end{array}$ \\
\hline$W P i b_{t}^{2}$ & - & - & - & $\begin{array}{c}-0.0167^{*} \\
(0.009)\end{array}$ \\
\hline$\lambda$ & - & $\begin{array}{c}0.0749^{* * *} \\
(0.025)\end{array}$ & - & - \\
\hline$\rho$ & - & - & $\begin{array}{l}.0650^{* *} \\
(0.025)\end{array}$ & $\begin{array}{c}0.0715^{\star \star *} \\
(0.025) \\
\end{array}$ \\
\hline Informação de Akaike & -3522.74 & -3825.74 & -3823.97 & -3828.07 \\
\hline
\end{tabular}

Nota: ${ }^{* *}$ Significant at a significance level of $1 \%$; ${ }^{* *}$ Significant at a significance level of $5 \%$.

Fonte: Resultado da pesquisa.

Em relação ao sinal das variáveis do Clube de Convergência Norte (Tabela 3) e controle algumas diferenças podem ser observadas: a primeira é em relação a variável motocicleta por mil habitantes $\left(\mathrm{Moto}_{t}\right)$ que por sua vez, revela-se negativa no Clube Norte e positiva no Clube Sul (Tabela 4), ao passo que variável motocicleta

\footnotetext{
${ }^{15}$ Segue a metodologia de Wooldridge (2010), para inclusão de Dummy de interação temporal.
} 
defasada espacialmente há uma inversão de sinal, retratando uma possível diferença em relação a como a motocicleta pode ser representada em cada clube, de modo que no clube sul a motocicleta pode ser um bem complementar ao automóvel, já no Clube Norte um bem substituto este resultado corrobora com os estudos de Betucci (2011). O segundo clube de convergência compreende as regiões sul, sudeste e centro-oeste e será chamado de Clube de Convergência Sul apresentado na Tabela.

Tabela 4 - O comportamento da taxa de crescimento da demanda de automóveis por mil habitantes do Clube de Sul - regiões Sul, Sudeste e Centro Oeste do Brasil, 2004 a 2015.

\begin{tabular}{|c|c|c|c|c|}
\hline \multirow{2}{*}{ VARIÁVEIS } & \multicolumn{4}{|c|}{ Painel Espacial ${ }^{16}$} \\
\hline & Efeito Fixo (I) & SEM (II) & SAR (III) & SDM (IV) \\
\hline Auto $(\omega)_{t-1}$ & $\begin{array}{c}-0.0339^{* * *} \\
(0.001)\end{array}$ & $\begin{array}{c}-0.1199^{* \star *} \\
(0.008)\end{array}$ & $\begin{array}{c}-0.1129^{\star \star *} \\
(0.007)\end{array}$ & $\begin{array}{c}-0.1299^{\star * *} \\
(0.008)\end{array}$ \\
\hline Moto $(\rho)_{t}$ & $\begin{array}{r}-0.0011 \\
(0.001)\end{array}$ & $\begin{array}{c}0.0104^{* * *} \\
(0.003)\end{array}$ & $\begin{array}{c}0.0104^{\star * *} \\
(0.003)\end{array}$ & $\begin{array}{c}0.0095^{\star *} \\
(0.004)\end{array}$ \\
\hline Onibus $(\rho)$ t & $\begin{array}{l}0.0012 \\
(0.001)\end{array}$ & $\begin{array}{c}0.0076^{* * *} \\
(0.002)\end{array}$ & $\begin{array}{c}0.0073^{* * *} \\
(0.002)\end{array}$ & $\begin{array}{c}0.0074^{* *} \\
(0.002)\end{array}$ \\
\hline Densidade popt & $\begin{array}{r}-0.0000 \\
(0.001)\end{array}$ & $\begin{array}{c}0.2559^{* \star *} \\
(0.023)\end{array}$ & $\begin{array}{c}0.2602^{* * *} \\
(0.022)\end{array}$ & $\begin{array}{c}0.2194^{\star * *} \\
(0.026)\end{array}$ \\
\hline Densidade pop $_{t}^{2}$ & $\begin{array}{c}-0.0000 \\
(0.001)\end{array}$ & $\begin{array}{c}-0.0262^{\star \star *} \\
(0.003)\end{array}$ & $\begin{array}{c}-0.0271^{* * *} \\
(0.003)\end{array}$ & $\begin{array}{c}-0.0218^{* * *} \\
(0.003)\end{array}$ \\
\hline $\mathrm{Pib}_{\mathrm{t}}$ & $\begin{array}{c}0.0452^{* * *} \\
(0.005)\end{array}$ & $\begin{array}{c}0.0972^{* * *} \\
(0.009)\end{array}$ & $\begin{array}{c}0.0893^{* * *} \\
(0.008)\end{array}$ & $\begin{array}{c}0.1000^{* * *} \\
(0.010)\end{array}$ \\
\hline$P i b_{t}^{2}$ & $\begin{array}{c}-0.0080^{* * *} \\
(0.000)\end{array}$ & $\begin{array}{c}-0.0157^{* * *} \\
(0.001)\end{array}$ & $\begin{array}{c}-0.0147^{* * *} \\
(0.001)\end{array}$ & $\begin{array}{c}-0.0155^{\star \star *} \\
(0.001)\end{array}$ \\
\hline W Auto $(\omega)_{t-1}$ & 1. & 1 & 1 & $\begin{array}{c}0.0995^{\star * *} \\
(0.022)\end{array}$ \\
\hline$W$ Moto $(\rho)_{t}$ & - & - & - & $\begin{array}{l}-0.0023 \\
(0.007)\end{array}$ \\
\hline W Onibus $(\rho)_{t}$ & - & - & - & $\begin{array}{l}0.0041 \\
(0.004)\end{array}$ \\
\hline W Densidade popt & - & - & - & $\begin{array}{l}0.0054 \\
(0.070)\end{array}$ \\
\hline W Densidade pop ${ }_{t}^{2}$ & - & - & - & $\begin{array}{l}-0.0105 \\
(0.009)\end{array}$ \\
\hline$W P_{i b}$ & - & - & - & $\begin{array}{c}-0.0987^{* * *} \\
(0.025)\end{array}$ \\
\hline$W P i b_{t}^{2}$ & - & - & - & $\begin{array}{c}0.0076^{\star *} \\
(0.003)\end{array}$ \\
\hline$\lambda$ & - & $\begin{array}{c}0.1647^{* * *} \\
(0.020)\end{array}$ & - & 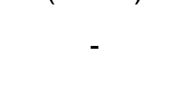 \\
\hline$\rho$ & - & - & $\begin{array}{c}0.1524^{\star * *} \\
(0.019)\end{array}$ & $\begin{array}{c}0.4170^{\star \star *} \\
(0.038)\end{array}$ \\
\hline Informação de Akaike & -15501.86 & -16213.12 & -16208.86 & -16281.26 \\
\hline
\end{tabular}

Outra variável importante é o PIB defasado tanto na sua forma linear quanto na quadrática. Observa-se que existem relações novamente opostas entre os clubes de convergência, ao passo que a microrregião de referência no Clube Sul apresenta um sinal positivo da variável linear e negativo da variável na sua forma quadrática.

\footnotetext{
${ }^{16}$ Segue a metodologia de Wooldridge (2010), para inclusão de Dummy de interação temporal
} 
$\mathrm{Na}$ prática pode se observar spillover positivo do PIB no envoltório das microrregiões no Clube Sul, ou seja, quando há crescimento do PIB por mil habitantes de uma microrregião, na média há também um crescimento da demanda por mil habitantes de automóveis, ao passo que, se a microrregião já apresenta elevado PIB por mil habitantes ocorre uma dinâmica inversa havendo influência negativa na taxa de crescimento da demanda de automóveis per capita.

No tocante a criação dos clubes de convergência, esse fator pode ser observado duas maneiras: primeiramente através do teste dos resíduos do resultado das regressões e, a segunda a partir das observações da Tabela 5 apresentando a velocidade de convergência e de meia vida.

No que se refere aos testes dos resíduos, pode-se observado de forma mais detalhados no (Apêndice $B$ ) é possível observar que os resíduos dos modelos analisados a partir do painel de Efeito Fixo, apresentam em todos os anos a presença de espaço, ou seja, o l de Moran é em média maior que 0,10 e significativo.

Com relação ao resultado do modelo espacial após a regressão de painel durbin espacial de efeito fixo ( $s d m f e$ ) observou-se para o caso do modelo Brasil condicional que a regressão $s d m$ conseguiu reduzir o espaço em todos os anos de estudo na medida em que houve exclusão total do espaço em 7 dos 12 anos analisados.

No caso da região norte o modelo ( $\mathrm{sdm}$ fe) conseguiu resultados ainda melhores, onde houve exclusão do espaço em cerca de 10 dos 12 anos analisados, este fato revela que o modelo conseguiu apresentar resultados satisfatórios para o clube norte de convergência.

Por fim, o clube sul de convergência resultou em retirada do espaço de 4 dos 12 anos, ou seja, há fatores não analisados que resultam na continuidade do espaço.

$\mathrm{Na}$ tentativa de obter melhores resultados para esta região, adequou-se o modelo fazendo primeiramente um corte da região centro oeste do sul e sudeste ao mesmo tempo que se incluiu uma dummy para os anos outliers, porém os resultados foram insatisfatórios a nível de presença de espaço nos resíduos para ambas tratativas.

De qualquer forma, este resultado não invalidam a discussão, pois segundo ALMEIDA (2012), o painel espacial não necessariamente retira todo o espaço do 
fenômeno estudado, pois alguns objetos de estudo são muito sensíveis a outras variáveis.

Em relação a homogeneização da frota de automóveis ao obter o valor do $\beta$ convergência, é possível estimar a velocidade dessa homogeneização, esta por sua vez representa o tempo de convergência ao ano necessário para que microrregiões alcancem metade do caminho (denominado meia-vida, $\tau$ ) que os separa dos seus respectivos estados estacionários, conforme apresentado na Tabela 5.

Tabela 5 - Velocidade de convergência e de meia vida para demanda de automóveis do Brasil, para o período de 2004 a 2015.

\begin{tabular}{lccc}
\hline \multicolumn{1}{c}{ Modelo } & Beta Convergência & Velocidade & $\begin{array}{c}\text { Meia Vida } \\
\text { (anos) }\end{array}$ \\
\hline Brasil Absoluto & -0.0914 & $0.80 \%$ & 87 \\
Brasil Condicional & -0.1197 & $1.06 \%$ & 65 \\
Clube de Convergência Sul & -0.1299 & $1.16 \%$ & 60 \\
Clube de Convergência Norte & -0.1196 & $1.06 \%$ & 65 \\
\hline
\end{tabular}

Fonte: Resultado da pesquisa.

Os resultados apontaram para um progresso de convergência do modelo Brasil Absoluto da demanda efetiva de automóveis por mil habitantes de 0,8\% ao ano, ritmo de convergência inferior quando comparado ao modelo Brasil Condicional, que atingiu 1,06\% ao ano. Em outras palavras, quando há um controle a partir de variáveis estruturais podem-se observar uma velocidade maior de convergência. $O$ tempo enfrentado para que as microrregiões alcancem a metade do trajeto é denominado tempo para meia vida, que levará as microrregiões aos seus estados estacionários, em média, de acordo com o resultado obtido no primeiro modelo de 87 anos e no modelo ponderado pelas variáveis condicionantes em 65 anos.

Observou-se que existe um tempo similar ao considerar o modelo Brasil Condicional e modelo Clube Norte ambos apresentaram um mesma velocidade e tempo de meia vida, por outro lado o Clube Sul apresentou uma velocidade de convergência superior chegando ao seu estado de meia vida em 60 anos.

\section{Considerações Finais}

O presente trabalho investigou os processos de convergência absoluta, condicional e dos clubes norte e sul para microrregiões brasileiras no período 2004 a 2015, considerando também a dependência espacial nas formas de erro, de defasagem e de transbordamentos 
das variáveis explicativas. Tais análises locais buscaram averiguar a existência de coeficientes $\beta$ e de velocidades de convergência específicos para cada análise.

Assim, para atingir os objetivos propostos foi necessário averiguar a dinâmica espaço-temporal da demanda efetiva de automóveis nas microrregiões brasileiras, afim de localizar os padrões de associação espacial, buscando clusters espaciais significativos entre as microrregiões brasileiras utilizando ferramentas de Análise Exploratória de Dados Espaciais (AEDE), analise de Cluster e da Econometria Espacial.

Por meio das técnicas mencionadas, identificou-se que, em geral, microrregiões com alta taxa de crescimento por mil habitantes da demanda efetiva de automóveis estão circundadas por microrregiões também com alta taxa de crescimento (e vice-versa). As microrregiões localizadas na Região Norte e Nordeste do país, concentram os principais clusters AA da taxa de crescimento da demanda efetiva per capita.

Foi possível verificar que não houve deslocamento do maior cluster AA da frota per capita, que ao longo do período estudado manteve-se concentrada basicamente na região sul e sudeste.

A presença de dependência espacial tornou necessário a utilização do Painel de Dados em sua versão espacial para verificar quais variáveis condicionam a taxa de crescimento da demanda efetiva por mil habitantes de automóveis nas microrregiões brasileiras.

As estimações indicaram que microrregiões que apresentaram uma menor demanda efetiva por mil habitantes no período inicial tenderam a ter maiores taxas de crescimento de suas frotas, evidenciando um processo de homogeneização ao longo do território brasileiro. Além disso, as variáveis estruturais mostraram-se satisfatórias tendo seu grau de significância em $1 \%$.

Também foi possível identificar o transbordamento espacial positivo para a taxa de crescimento da demanda efetiva per capita, captado pelo coeficiente de autocorrelação espacial positivo e significativo a $1 \%$. Esse resultado corrobora aqueles encontrados Cintra (2014), Haddad (2015), Lucinda (2017), que identificaram externalidades positivas e que têm o potencial de alavancar o dinamismo nas regiões vizinhas.

Assim, o resultado aqui encontrado contribui para a literatura uma vez que foi possível comprovar a importância dos spillovers positivos para as microrregiões brasileiras, podendo possivelmente atuar como indutor de concentração espacial, o que de fato foi identificado com a AEDE.

A partir do controle da convergência por meio da criação de clubes de convergência, foi possível obter resultados para as microrregiões que apresentaram dinâmicas semelhantes em termos de velocidade e tempo de convergência, permitindo que este trabalho contribua especificamente à literatura ao trazer as diferença da relação da motocicleta per capita, nos Clubes Norte e Sul que por sua vez revelou-se negativa no clube 
norte e positiva no Clube Sul, uma diferença em relação como a motocicleta pode ser representada em cada clube, de modo que no clube sul a motocicleta pode ser um bem complementar ao automóvel, já no clube norte um bem substituto.

Por fim, em relação aos clubes de convergência, o modelo clube norte se mostrou robusto no que tange as estratégias econométricas propostas, entretanto mesmo controlando dependência espacial e heterogeneidade estrutural, de acordo com o Apêndice B na Tabela 14, onde é apresentado os I de Moran dos resíduos das microrregiões clube sul de 2004 a 2015. Não foi possível através do modelo proposto, retirar totalmente a heterogeneidade espacial no modelo clube sul, recomenda-se em trabalhos futuros investigações pontuais.

Incentiva-se por meio desse trabalho, entretanto através de um ponto não abordado diretamente, mas que merece atenção dos pesquisadores, refere-se à relação das questões de política de incentivo para impulsionar a demanda de automóvel. Recomenda-se em trabalhos futuros, a verificação da hipótese dos possíveis efeitos das políticas de incentivo governamentais, a ponto de analisar como distintas regiões respondem a incentivos, a partir desse trabalho é possível indicar que incentivos fiscais podem resultar em diferentes reações nas microrregiões do Brasil dada a suas caraterísticas estruturais e heterogeneidade no que tange demanda efetiva de automóveis.

\section{REFERÊNCIAS}

ALMEIDA, E. S. Econometria espacial aplicada. Campinas - SP: Editora Alínea, 2012.

ALMEIDA, S. E.; PEROBELLI, S. F.; FERREIRA, C. G. P. Existe convergência espacial da produtividade agrícola no Brasil?. Revista de Economia e Sociologia Rural, v. 46, n. 1, p. 31-52, 2008.

ANSELIN. Local indicators of spatial association - LISA. Geographical Analysis, v. 27, n. 2, p. 93-115, Apr. 1995.

BARAT, J. Logística, transporte e desenvolvimento econômico. Editora CLA, 2007.

BARRO, Robert J.; SALA-I-MARTIN, Xavier. Convergence. Journal of political Economy, v. 100 , n. 2, p. 223-251, 1992.

BARROS, H. P.; FREITAS JR, M. A.; CAMPOS, F. L. L.; HILGEMBERG, T. C. Sistema de aluguéis de bicicleta: externalidades positivas econômicas e ambientais. Ecopar, 2017. Disponível em :<http://sites.uem.br/ecopar/artigos-aprovados/ecopar-1/area-42013 economia-agricola-e-do-meio-ambiente> acessado em 20/01/2018.

BAUMOL, William J. Productivity growth, convergence, and welfare: what the long-run data show. The American Economic Review, p. 1072-1085, 1986. 
BATISTELLA, M.; BRONDIZIO, E. S. Uma estratégia integrada de monitoramento e análise do impacto ambiental de assentamentos rurais na Amazônia. Monitoramento e Contabilização de Impactos Ambientais. Campinas, Editora: Unicamp, 2004.

BAUMGARTEN JR, L. A. Demanda de automóveis no Brasil. Revista Brasileira de Economia, v. 26, n. 2, p. 203-297, 1972.

BERRY, S.; LEVINSOHN, J.; PAKES, A. Automobile prices in market equilibrium. Journal of the Econometric Society, p. 841-890, 1995.

BERTUSSI, Geovana Lorena; FIGUEIREDO, L. de. Investigando a hipótese de convergência na América Latina e no Leste Asiático: uma abordagem de regressão quantílica. Belo Horizonte: UFMG/Cedeplar, 2009.

BERTUCCI, O. J. Benefícios do transporte coletivo. 2011.

BRITO, D. G. Aumento na demanda de automóveis: políticas e instrumentos para reduzir os impactos no meio ambiente. 2011.

CAMAGNI, R.; GIBELLI, C. M.; RIGAMONTI, P. Urban mobility and urban form: the social and environmental costs of different patterns of urban expansion. Ecological economics, $v$. 40, n. 2, p. 199-216, 2002.

CARVALHO, Carlos Henrique R.; PEREIRA, Rafael Henrique M. Gastos das famílias brasileiras com transporte urbano público e privado no Brasil: uma análise da POF 2003 e 2009. 2012.

CAO, X.; MOKHTARIAN P.L. The Future Demand for Alternative Fuel Passenger Vehicles: A Preliminary Literature Review. University of California - Davis, 2003. Disponível em:< http://aqp.engr.ucdavis.edu>, acessado em 21/08/2018.

CASTAÑON, N. U. A bicicleta como veículo de mobilidade urbana sustentável. CEP, v. 36036, p. 390, 2017.

CELBIS, G. M.; CROMBRUGGHE, D. Internet infrastructure and regional convergence: Evidence from Turkey. Papers in Regional Science, v. 97, n. 2, p. 387-409, 2018.

CINTRA, M. Os custos dos congestionamentos na cidade de São Paulo. 2014.

CNT, Confederação Nacional do Transporte. 2018. Disponível em: https://www.cnt.org.br/home, acessado em 05/10/2018.

CORRÊA, L. R. et al. O espaço urbano. Editora: Ática, 1989.

COELHO, Rodrigo Lara Pinto. Dois ensaios sobre a desigualdade de renda dos municípios brasileiros. Two essays in income inequality of Brazilian municipalities]. Master's thesis, Centro de Desenvolvimento e Planejamento Regional, Universidade Federal de Minas Gerais (Cedeplar-UFMG), 2006.

COSTA JR, J. C.; FANTINATTI, M. A.; TELES, K. V. Política fiscal direcionada no Brasil. 2018.

COSTA, S. M.; RAMOS, R; SILVA, R. N. A. Índice de mobilidade urbana sustentável para cidades brasileiras. 2007.

COSTA, S. D. R. Análise econômico-financeira do mercado automotivo brasileiro (2007 a 2011). 2014. 
CRAMER, J.; KRUEGER, B. A. Disruptive change in the taxi business: The case of Uber. American Economic Review, v. 106, n. 5, p. 177-82, 2016.

CRISTO, F. O hábito de usar automóvel tem relação com o transporte coletivo ruim? 2014.

DE ALMEIDA, S. A. M.; GUANZIROL, E. C. Análise exploratória espacial e convergência condicional das taxas de crimes em Minas Gerais nos anos 2000. ANPEC, 2014.

DE AZEVEDO MEINERS, M. E. W. Impactos regionais dos investimentos automobilísticos no Paraná. Revista Paranaense de Desenvolvimento, n. 94, p. 29-48, 2011.

DE FÁTIMA FIGUEIRÊDO, C.; MAIA, A. L. M. O Uso da Motocicleta e a Inclusão Social, 2013.

DE FRANÇA, R. M. T. Indústria Automobilística: Globalização Produtiva e Atividades de P\&D. Mercado de Trabalho: Árdua Recuperação, p. 33, 2018.

DE MOURA VOGT, C.; DE LUCINDA, R C. Custos de procura e dispersão de preços de gasolina e etanol no mercado brasileiro de combustíveis: evidências do município de São Paulo. Análise Econômica, v. 35, n. 68, 2017.

DE OLIVEIRA FARIA, E.; ANTIGÜIDADE, N. História dos transportes terrestres no mundo. Universidade Federal do Rio de Janeiro, 2004. Disponível em:< http://www. transitocomvida. ufrj. br/download/Hist \% F3ria\% 20dos\% 20transportes\% 20terrestres. pdf.>

DE OLIVEIRA, M. P.; GONÇALVES, E.; DE ALMEIDA, S. E. Existe convergência de patenteamento no Brasil?. Revista Brasileira de Inovação, v. 15, n. 2, p. 335-364, 2016.

DE VASCONCELLOS, A. E.; DE CARVALHO, R. H. C.; PEREIRA, M. H. R. Transporte e mobilidade urbana. Texto para Discussão, Instituto de Pesquisa Econômica Aplicada, 2011.

DEMAIO, P. Bike-sharing: History, impacts, models of provision, and future. Journal of Public Transportation, v. 12, n. 4, 2009.

DENATRAN, Departamento Nacional de Trânsito, 2018. Disponível em: <https://www.denatran.gov.br/> acessado em 06/08/2018.

DESOUZA, A. S. et al. A tributação nas vendas de automóveis no Brasil: quem paga a maior parte da conta?. Revista Economia, v. 11, n. 3, p. 559-596, 2010.

DIVALL, C. From rail to road and back again?: A century of transport competition and interdependency. Routledge, 2016.

DUARTE, F.; LIBARDI, R. Introdução à mobilidade urbana. Editora: Jurua, 2012.

ELHORST, J. Paul. Specification and estimation of spatial panel data models. International regional science review, v. 26, n. 3, p. 244-268, 2003.

FERRAZ, C.; FIUZA, E.; MOTTA, S. R. Medindo os efeitos da regulação ambiental em mercados de oligopólio: $O$ caso da poluição automotiva. 2001.

FERREIRA, C. P.; MALLIAGROS, Thomas G. Investimentos, fontes de financiamento e evolução do setor de infra-estrutura no Brasil: 1950-1996. 1999. 
FREITAG, D. R. History of wheels for off-road transport. Journal of Terramechanics, $v$. 16, n. 2, p. 49-68, 1979.

FREITAS JR, A.; BATISTA, P. H. Dinâmica Espaço-Temporal da Produção Bovina no Brasil: o Avanço da Fronteira Agrícola na Amazônia de 1990 a 2015, uma análise espacial com dados em painel 1 . Disponível em: <https://www.brsa.org.br/fotos/artigo12018-06-20-13-06-32.pdf>. Acesso em: 5 jan. 2019.

FREITAS JR, A.; et al. Análise de algumas variáveis determinantes para o uso da bicicleta no cotidiano do estudante de economia da UFPR e prefácio ao sistema de aluguéis de bicicletas. 2016.

FREITAS, M. V.; GONÇALVES, E.; MONTENEGRO, R. L. G. Desigualdade tecnológica, convergência espacial e transbordamentos: uma análise por estados brasileiros (19902001). Revista Brasileira de Estudos Regionais e Urbanos, v. 4, p. 1-21, 2010.

FREITAS, V. M.; ALMEIDA, E. Existe realmente convergência de renda entre países?. Estudos Econômicos. São Paulo, v. 45, n. 2, p. 287-316, 2015. Disponível em:<http://www.scielo.br/scielo.php?script=sci_arttext\&pid=S0101-

$41612015000200287 \& \operatorname{lng}=$ en\& $\mathrm{nrm}=$ iso $>$.

FREITAS, V. M.; GONÇALVES, E.; MONTENEGRO, G. L. R. Desigualdade tecnológica, convergência espacial e transbordamentos: uma análise por estados brasileiros (19902001). Revista Brasileira de Estudos Regionais e Urbanos, v. 4, n. 2, p. 1-18, 2010.

FRIEDMANN, John et al. Empowerment: the politics of alternative development. Blackwell, 1992.

GALOR, Oded; TSIDDON, Daniel. Technological progress, mobility and economic growth. 1996.

GIVONI, M.; RIETVELD, P. The access journey to the railway station and its role in passengers' satisfaction with rail travel. Transport Policy, v. 14, n. 5, p. 357-365, 2007.

GLAESER, L. E. et al. Growth in cities. Journal of political economy, v. 100, n. 6, p. 11261152, 1992.

GRILICHES, Zvi. The search for R\&D spillovers. National Bureau of Economic Research, 1991.

GOLDBERG, K. P.; VERBOVEN, F. Market integration and convergence to the Law of One Price: evidence from the European car market. Journal of international Economics, v. 65, n. 1, p. 49-73, 2005.

GONÇALVES, E. A distribuição espacial da atividade inovadora brasileira: uma análise exploratória. Estudos Econômicos, v. 37, n. 2, p. 405-433, 2007.

GONDIM, F. M. A travessia no tempo: homens e veículos, da mitologia aos tempos modernos. Universidade de Brasília, 2014.

GÔMARA, Antônio Rúbio de Barros. O transporte rodoviário interestadual e internacional de passageiros: Um acrescentamento histórico. Brasília: ABRATI, 1999.

HADDAD, A. E.; VIEIRA, S. R. Mobilidade, acessibilidade e produtividade: nota sobre a valoração econômica do tempo de viagem na região metropolitana de São Paulo. Núcleo de Economia Regional e Urbana, Universidade de São Paulo, 2015. 
ISLAM, Nazrul. What have we learnt from the convergence debate?. Journal of economic surveys, v. 17, n. 3, p. 309-362, 2003.

JACOBS, J. The Life of Cities. Random House, 1969.

JOHNSON, Paul A.; TAKEYAMA, Lisa N. Convergence among the US states: Absolute, conditional, or club?. 2003.

JOHNSON, Richard A. Wichern. DW Applied Multivariate Statistical Analysis. New Jersey: Prentice-Hall, Inc, v. 1, p. 998, 2007.

KEMP, L. E. Uma História do Weston \& Gauley Bridge Turnpike. West Virginia Univ Morgantown, 1979.

KRUGMAN, Paul. Increasing returns and economic geography. Journal of political economy, v. 99, n. 3, p. 483-499, 1991.

LAURINI, Márcio et al. Clubes de convergência de renda para os municípios brasileiros: uma análise não-paramétrica. documento presentado en el XXV Encuentro brasileño de econometría, Porto Seguro, 2003.

LIMA, O. M. L. Retrospectiva do transporte brasileiro: As conquistas e os entraves na transicão dos séculos XX e XXI. Inter-American Development Bank, 2005.

LOPES. F. A. M. O fracasso da Comissão Mista Brasil - Estados Unidos (CMBEU) e os rumos da política econômica no segundo Governo Vargas (1951 - 1954). Dissertação (Mestrado em Economia Política), Pontifícia Universidade Católica -PUC, São Paulo, 2009

LOTUFO, O. J. Oikos: Reintegrando natureza e civilização. Revista Labverde, n. 2, p. 108127, 2011.

LÜBECK, M. R. et al. Diga-Me no que andas e te Direi quem és: Aspectos de Influência nos Jovens da Classe C Brasileira para Adquirir Automóveis. Revista Brasileira de Marketing, v. 13, n. 3, p. 17-35, 2014.

LUCINDA, R. C. et al. The economics of sub-optimal policies for traffic congestion. Journal of Transport Economics and Public, v. 51, n. 4, p. 225-248, 2017.

MACHADO, C. D; VIANNA, B. S. G. UMA ANÁLISE DOS CUSTOS DA MOBILIDADE URBANA NO BRASIL: PERDAS DO PIB COM DESLOCAMENTOS. Revista Brasileira de Estudos Regionais e Urbanos, v. 11, n. 2, p. 152-172, 2017.

MAKSIMKIN, I. et al. Development of Road Transportation. 2018.

MANKIW, G. N.; ROMER, D.; WEIL, N. D. A contribution to the empirics of economic growth. The quarterly journal of economics, v. 107, n. 2, p. 407-437, 1992.

MARICATO, E. O impasse da política urbana no Brasil. Editora Vozes Limitada, 2017.

MASCARENHAS, R. R.; RIBEIRO FILHO, V. Mobilidade urbana nos países em desenvolvimento: Uma analogia do transporte público urbano a partir da opção rodoviária e do automóvel no Brasil. CaderNAU, v. 9, n. 1, p. 155-171, 2016.

MENEZES, S. M. Mobilidade urbana e a contribuição das estratégias de gestão de demanda na cidade de Salvador. 2014. 
MIAN, Atif; SUFI, Amir. The effects of fiscal stimulus: Evidence from the 2009 cash for clunkers program. The Quarterly journal of economics, v. 127, n. 3, p. 1107-1142, 2012.

MISHRA, B. et al. A Spatial Analysis Of Creative Class Worker Growth Convergence In Us Counties. Romanian Journal of Regional Science, v. 10, n. 1, p. 43-66, 2016.

MONTENEGRO, L. R.; GONÇALVES, E.; ALMEIDA, E. Dinâmica espacial e temporal da inovação no estado de São Paulo: uma análise das externalidades de diversificação e especialização. Estudos Econômicos, v. 41, n. 4, p. 743-776, 2011.

MOSQUEIRA, M. T. Reabilitação da Região da Luz-Centro Histórico de São Paulo: projetos urbanos e estratégias de intervenção. Tese de Doutorado. 2007.

MURPHY, E.; USHER, J. Uma análise do papel da partilha de bicicletas numa cidade europeia: o caso de Dublin. In: Paper apresentado na Rede Irlandesa de Pesquisa de Transportes, University College Cork - Irlanda. IRTN, 2011.

NASCIMENTO, H. B. Formação da indústria automobilística brasileira: política de desenvolvimento industrial em uma economia dependente. Universidade de São Paulo, Instituto de Geografia, 1976.

NASCIMENTO, T. B;; DE ÁVILA MONTINI, A. MODELOS PARA PROJEÇÃO DE DEMANDA NA INDÚSTRIA AUTOMOBILÍSTICA BRASILEIRA. Pesquisa-

Desenvolvimento e Gestão, v. 17, n. 1, 2014.

NORTH, Douglass. Instituciones, câmbio institucional y desempeño económico. Mexico. Fondo de Cultura Económica. 1995.

OJIMA, R. et al. O estigma de morar longe da cidade: repensando o consenso sobre as" cidades-dormitório. Cadernos Metrópole, v. 12, n. 24, 2010.

OLIVEIRA, P. M; GONÇALVES, E.; ALMEIDA, E.; Existe convergência de patenteamento no Brasil?. Revista Brasileira de Inovação, Campinas -SP, 15 (2), p. 335-364, julho/dezembro 2016.

PEREIRA, T.; CARVALHO, A. Abertura comercial, mark ups setoriais domésticos e rentabilidade relativa das exportações. 1998.

PEROBELLI, F. S.; FARIA, W. R.; FERREIRA, P. G. C. Análise da convergência espacial do PIB por mil habitantes no estado de Minas Gerais. Revista Brasileira de Estudos Regionais e Urbanos, v. 1, n. 1, p. 85-113, 2009.

PIRES, M. C. C. Multiplicadores fiscais no Brasil: uma contribuição ao debate sobre políticas fiscais anticíclicas. In: XXXVII ENCONTRO NACIONAL DE ECONOMIA, ANPEC. 2009.

QUAH, T. D. Empirics for economic growth and convergence. European economic review, v. 40, n. 6 , p. $1353-1375,1996$.

REIS, S. V. C. et al. O efeito da mobilidade urbana na renda do trabalhador no Distrito Federal. Revista Eletronica Gestão \& Saúde, v. 4, n. 3, p. 3239-3262, 2014.

RESENDE, V. T. P; SOUSA, R. P. Mobilidade urbana nas grandes cidades brasileiras: um estudo sobre os impactos do congestionamento. Simpósio de Administração da Produção, Logística e Operações Internacionais, FGV, 2009.

REY, J. S.; MONTOURY, B. D. US Regional income convergence: a spatial econometric perspective. Regional Studies, v. 33, n. 2, p. 143-156, 1999. 
Richardsson, B. C. Sustainable transport:analysis frameworks. Journal of Transport Geograph. v. 13, p. 29-39. 2005.

RODRIGUES, A. R. P. Introdução aos sistemas de transporte no Brasil e à logística internacional. Edições Aduaneiras, 2008.

RUBIM, B.; LEITÃO, S. O plano de mobilidade urbana e o futuro das cidades. Estudos Avançados, v. 27, n. 79, p. 55-66, 2013.

SALA-I-MARTIN, X. X. The classical approach to convergence analysis. The economic journal, p. 1019-1036, 1996.

SANTOS, M. M. M. A. Reestruturação da indústria automobilística na América do Sul. 2001.

SANTOS, G. et al. Part I: Externalities and economic policies in road transport. Research in transportation economics, v. 28, n. 1, p. 2-45, 2010.

SANTOS, D. J. et al. Série temporal de índices de Redes Complexas em mobilidade urbana. Proceeding series of the Brazilian Society of Computational and Applied Mathematics, v. 6, n. 1, 2018.

SCARINGELLA, S. R. A crise da mobilidade urbana em São Paulo. São Paulo em perspectiva, v. 15, n. 1, p. 55-59, 2001.

SCHUMPETER, J. A. Business Cycles: A Theoretical, Historical, and Statistical Analysis of the Capitalist Process, McGraw-Hill Book Company Inc., New York, 1939.

SOUZA, U. E. O transporte público urbano como suporte para o desenvolvimento do turismo em Natal-RN. Trabalho de Conclusão de Curso. Universidade Federal do Rio Grande do Norte. 2013.

TEIXEIRA E HESPANHOL. A Região Centro-Oeste no contexto das mudanças agrícolas ocorridas no período após 1960. Revista da associação de geógrafos brasileiros. p. 52, 1996.

TEIXEIRA, P. A. F. R.; BERTELLA, A. M. Distribuição Espaço-Temporal da Produtividade Média do Café em Minas Gerais: 1997-2006. Análise Econômica, v. 33, n. 63, 2015.

TOOLKIT, BEHAVIOURAL INSIGHTS. Social Research and Evaluation Division, Department for Transport, November at al 2011.

URRY, J. Mobilities: new perspectives on transport and society. Routledge, 2016.

VASCONCELLOS, A. E. O custo social da motocicleta no Brasil. Revista dos Transportes Públicos, v. 30, p. 31, 2008.

VASCONCELOS, A. E. O que é trânsito. Brasiliense, 2017.

VERBOVEN, F. International price discrimination in the European car market. Rand Journal of Economics, v. 27, n. 2, p. 240-268, 1996.

WILKS, S. D. Cluster analysis. In: International geophysics. Academic press, 2011. p. 603616. 


\section{NOTAS DE AUTOR}

\section{CONTRIBUIÇÃO DE AUTORIA}

Adirson Maciel de Freitas Junior - Concepção. Coleta de dados, Análise de dados, Elaboração do manuscrito, revisão e aprovação da versão final do trabalho

Cleise Maria Tupich Hilgemberg - Concepção e elaboração do manuscrito. Coleta de dados Participação ativa da discussão dos resultados; Revisão e aprovação da versão final do trabalho.

\section{FINANCIAMENTO}

Não se aplica.

\section{CONSENTIMENTO DE USO DE IMAGEM}

Não se aplica.

\section{APROVAÇÃO DE COMITÊ DE ÉTICA EM PESQUISA}

Não se aplica.

\section{CONFLITO DE INTERESSES}

Não se aplica.

\section{LICENÇA DE USO}

Este artigo está licenciado sob a Licença Creative Commons CC-BY. Com essa licença você pode compartilhar, adaptar, criar para qualquer fim, desde que atribua a autoria da obra.

\section{HISTÓRICO}

Recebido em: 09-11-2019

Aprovado em: 14-12-2020

Apêndice A - Correlação Variáveis por modelo.

Tabela 6 - Correlação Variáveis Microrregiões Brasil - 2004 a 2015 - 6696

Observações

\begin{tabular}{c|cccccc}
\hline Correlação & Ln_Auto & Ln_Moto & Ln_Onib & Ln_densih & Ln_pib & Ln_densiEm \\
\hline Ln_Auto & 1.0000 & - & - & - & - & - \\
Ln_Moto & 0.4887 & 1.0000 & - & - & - & - \\
Ln_Onib & 0.5454 & -0.0874 & 1.0000 & - & - & - \\
Ln_densih & 0.4736 & 0.0513 & 0.2743 & 1.0000 & - & - \\
Ln_pib & 0.7148 & 0.4575 & 0.3276 & 0.2526 & 1.0000 & - \\
Ln_densiEm & $\mathbf{0 . 7 6 0 7}$ & $\mathbf{0 . 2 4 4 2}$ & $\mathbf{0 . 4 0 4 4}$ & $\mathbf{0 . 8 3 4 6}$ & $\mathbf{0 . 6 1 1 7}$ & $\mathbf{1 . 0 0 0 0}$ \\
\hline
\end{tabular}

Fonte: Resultado da pesquisa.

Tabela 7 - Correlação Variáveis Microrregiões Brasil - 2004 a 2015 - 6696 Observações

\begin{tabular}{c|ccccc}
\hline Correlação & Ln_Auto & Ln_Moto & Ln_Onib & Ln_densih & Ln_pib \\
\hline Ln_Auto & 1.0000 & - & - & - & - \\
Ln_Moto & 0.4887 & 1.0000 & - & - & - \\
Ln_Onib & 0.5454 & -0.0874 & 1.0000 & - & - \\
Ln_densih & 0.4736 & 0.0513 & 0.2743 & 1.0000 & - \\
Ln_pib & 0.7148 & 0.4575 & 0.3276 & 0.2526 & 1.0000 \\
\hline
\end{tabular}

Fonte: Resultado da pesquisa. 
Tabela 8 - Correlação Variáveis Microrregiões Clube Norte - 2004 a 2015 - 6696 Observações

\begin{tabular}{c|ccccc}
\hline Correlação & Ln_Auto & Ln_Moto & $L n_{-}$Onib & Ln_densih & $L n_{-}$pib \\
\hline Ln_Auto & 1.0000 & - & - & - & - \\
Ln_Moto & 0.5525 & 1.0000 & - & - & - \\
Ln_Onib & 0.5248 & -0.0277 & 1.0000 & - & - \\
Ln_densih & 0.5485 & 0.1107 & 0.3180 & 1.0000 & - \\
Ln_pib & 0.5096 & 0.4282 & 0.1894 & 0.1053 & 1.0000 \\
\hline
\end{tabular}

Fonte: Resultado da pesquisa.

Tabela 9 - Correlação Variáveis Microrregiões Clube Sul - 2004 a 2015 - 6696 Observações

\begin{tabular}{c|ccccc}
\hline Correlação & Ln_Auto & Ln_Moto & Ln_Onib & Ln_densih & Ln_pib \\
\hline Ln_Auto & 1.0000 & - & - & - & - \\
Ln_Moto & 0.2906 & 1.0000 & - & - & - \\
Ln_Onib & 0.2150 & -0.5212 & 1.0000 & - & - \\
Ln_densih & 0.5571 & -0.1122 & 0.1242 & 1.0000 & - \\
Ln_pib & 0.6488 & 0.3871 & 0.1274 & 0.3055 & 1.0000 \\
\hline
\end{tabular}

Fonte: Resultado da pesquisa

\section{Apêndice B - I de Moran dos Resíduos por modelo}

BRASIL

Tabela 10 - Painel de Efeitos Fixos - I de Moran dos resíduos das microrregiões brasileiras de 2004 a 2015.

\begin{tabular}{|c|c|c|c|c|c|c|c|}
\hline \multirow{2}{*}{ Ano } & \multicolumn{7}{|c|}{ Matriz Espaciais } \\
\hline & Q1 & $\mathrm{R} 1$ & K3 & K5 & K7 & K10 & K20 \\
\hline 2004 & $0,533^{*}$ & $0,533^{*}$ & $0,554^{*}$ & $0,519^{*}$ & $0,512^{*}$ & $0,493^{*}$ & $0,462^{*}$ \\
\hline 2005 & $0,528^{*}$ & $0,529^{*}$ & $0,519^{*}$ & $0,504^{*}$ & $0,486^{*}$ & $0,461^{*}$ & 0,436 * \\
\hline 2006 & $0,593^{*}$ & $0,593^{*}$ & $0,600^{*}$ & $0,576^{*}$ & $0,555^{\star}$ & $0,533^{*}$ & $0,502^{*}$ \\
\hline 2007 & $0,595^{*}$ & $0,594^{*}$ & $0,574^{*}$ & $0,568^{*}$ & $0,566^{*}$ & $0,543^{*}$ & $0,509^{*}$ \\
\hline 2008 & $0,606^{*}$ & $0,606^{*}$ & $0,609^{*}$ & $0,594^{*}$ & $0,579^{*}$ & $0,560^{*}$ & $0,521^{*}$ \\
\hline 2009 & $0,512^{*}$ & $0,512^{*}$ & $0,501^{*}$ & $0,495^{\star}$ & $0,478^{*}$ & $0,458^{*}$ & $0,417^{*}$ \\
\hline 2010 & $0,578^{*}$ & $0,578^{*}$ & $0,602^{*}$ & $0,566^{*}$ & $0,556^{*}$ & $0,533^{*}$ & $0,500^{*}$ \\
\hline 2011 & $0,613^{*}$ & $0,613^{*}$ & $0,615^{*}$ & $0,601^{*}$ & $0,586^{*}$ & $0,559^{*}$ & $0,512^{*}$ \\
\hline 2012 & $0,629^{*}$ & $0,629^{*}$ & $0,631^{*}$ & $0,605^{*}$ & $0,592^{*}$ & $0,560^{*}$ & $0,511^{*}$ \\
\hline 2013 & $0,625^{*}$ & $0,625^{*}$ & $0,628^{*}$ & $0,606^{*}$ & $0,591^{*}$ & $0,562^{*}$ & $0,512^{*}$ \\
\hline 2014 & $0,223^{*}$ & $0,225^{\star}$ & $0,202^{*}$ & $0,131^{*}$ & $0,101^{*}$ & $0,123^{*}$ & $0,122^{*}$ \\
\hline 2015 & $0,259^{*}$ & $0,250^{*}$ & $0,204^{*}$ & $0,186^{*}$ & $0,154^{*}$ & $0,162^{*}$ & $0,162^{*}$ \\
\hline
\end{tabular}

Nota: * Significante ao nível de $1 \%$

Fonte: Resultado da pesquisa.

Tabela 11 - Painel SDM Efeitos Fixos - I de Moran dos resíduos das microrregiões brasileiras de 2004 a 2015.

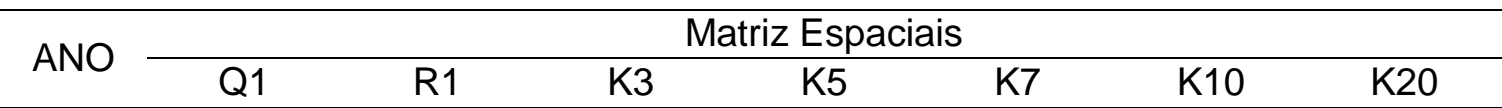




\begin{tabular}{llllllll}
\hline 2004 & $0,078^{*}$ & $0,078^{*}$ & 0,038 & 0,044 & 0,041 & 0,038 & $0,045^{*}$ \\
2005 & $0,076^{*}$ & $0,076^{*}$ & $0,087^{*}$ & 0,062 & 0,034 & 0,015 & 0,023 \\
2006 & $0,271^{*}$ & $0,271^{*}$ & $0,262^{*}$ & $0,236^{*}$ & $0,214^{*}$ & $0,188^{*}$ & $0,166^{*}$ \\
2007 & $-0,049$ & $-0,049$ & $-0,070$ & $-0.059^{*}$ & $-0,020$ & $-0,022$ & $-0,010$ \\
2008 & 0,014 & 0,014 & 0,036 & 0,041 & $0,044^{*}$ & $0,054^{*}$ & 0,036 \\
2009 & 0,042 & 0,042 & 0,025 & 0,030 & 0,035 & 0,030 & $0,032^{*}$ \\
2010 & $0,064^{*}$ & $0,066^{*}$ & $0,074^{*}$ & $0,089^{*}$ & $0,074^{*}$ & $0,070^{*}$ & $0,033^{*}$ \\
2011 & $0,090^{*}$ & $0,091^{*}$ & 0,056 & $0,056^{*}$ & $0,054^{*}$ & $0,057^{*}$ & $0,052^{*}$ \\
2012 & $0,365^{*}$ & $0,361^{*}$ & $0,340^{*}$ & $0,349^{*}$ & $0,337^{*}$ & $0,309^{*}$ & $0,237^{*}$ \\
2013 & $0,145^{*}$ & 0,145 & $0,134^{*}$ & $0,169^{*}$ & $0,145^{*}$ & $0,148^{*}$ & $0,124^{*}$ \\
2014 & $0,080^{*}$ & $0,081^{*}$ & 0,029 & $-0,027$ & $-0,070$ & $-0,039$ & $-0,024$ \\
2015 & $0,091^{*}$ & $0,091^{*}$ & 0,030 & $-0,024$ & $-0,062$ & $-0,033$ & $-0,012$ \\
\hline
\end{tabular}

Nota: * Significante ao nível de $1 \%$

Fonte: Resultado da pesquisa

\section{NORTE}

Tabela 12 - Painel de Efeitos Fixos - I de Moran dos resíduos das microrregiões clube norte de 2004 a 2015.

\begin{tabular}{cccccccc}
\hline \multirow{2}{*}{ Ano } & \multicolumn{7}{c}{ Matriz Espaciais } \\
\cline { 2 - 7 } & Q1 & R1 & K3 & K5 & K7 & K10 & K20 \\
\hline 2004 & $0,670^{*}$ & $0,670^{*}$ & $0,700^{*}$ & $0,655^{*}$ & $0,629^{*}$ & $0,605^{*}$ & $0,556^{*}$ \\
2005 & $0,667^{*}$ & $0,667^{*}$ & $0,697^{*}$ & $0,652^{*}$ & $0,621^{*}$ & $0,600^{*}$ & $0,555^{*}$ \\
2006 & $0,725^{*}$ & $0,724^{*}$ & $0,733^{*}$ & $0,702^{*}$ & $0,680^{*}$ & $0,665^{*}$ & $0,621^{*}$ \\
2007 & $0,719^{*}$ & $0,719^{*}$ & $0,712^{*}$ & $0,703^{*}$ & $0,687^{*}$ & $0,653^{*}$ & $0,598^{*}$ \\
2008 & $0,749^{*}$ & $0,750^{*}$ & $0,750^{*}$ & $0,732^{*}$ & $0,714^{*}$ & $0,688^{*}$ & $0,634^{*}$ \\
2009 & $0,699^{*}$ & $0,700^{*}$ & $0,704^{*}$ & $0,693^{*}$ & $0,670^{*}$ & $0,641^{*}$ & $0,585^{*}$ \\
2010 & $0,671^{*}$ & $0,672^{*}$ & $0,702^{*}$ & $0,666^{*}$ & $0,643^{*}$ & $0,620^{*}$ & $0,578^{*}$ \\
2011 & $0,733^{*}$ & $0,733^{*}$ & $0,747^{*}$ & $0,725^{*}$ & $0,700^{*}$ & $0,671^{*}$ & $0,616^{*}$ \\
2012 & $0,732^{*}$ & $0,732^{*}$ & $0,750^{*}$ & $0,724^{*}$ & $0,697^{*}$ & $0,666^{*}$ & $0,606^{*}$ \\
2013 & $0,735^{*}$ & $0,736^{*}$ & $0,751^{*}$ & $0,730^{*}$ & $0,702^{*}$ & $0,669^{*}$ & $0,610^{*}$ \\
2014 & $0,335^{*}$ & $0,335^{*}$ & $0,358^{*}$ & $0,212^{*}$ & $0,225^{*}$ & $0,217^{*}$ & $0,229^{*}$ \\
2015 & $0,375^{*}$ & $0,375^{*}$ & $0,331^{*}$ & $0,301^{*}$ & $0,295^{*}$ & $0,272^{*}$ & $0,260^{*}$ \\
\hline
\end{tabular}

Nota: * Significante ao nível de $1 \%$

Fonte: Resultado da pesquisa.

Tabela 13 - Painel SDM Efeitos Fixos - I de Moran dos resíduos das microrregiões clube norte de 2004 a 2015.

\begin{tabular}{cccccccc}
\hline \multirow{2}{*}{ Ano } & \multicolumn{7}{c}{ Matriz Espaciais } \\
\cline { 2 - 7 } & Q1 & R1 & K3 & K5 & K7 & K10 & K20 \\
\hline 2004 & 0,011 & 0,011 & $-0,040$ & $-0,019$ & $-0,002$ & $-0,002$ & 0,001 \\
2005 & 0,023 & 0,022 & 0,000 & $-0,002$ & $-0,028$ & $-0,028$ & 0,007 \\
2006 & $0,236^{*}$ & $0,234^{*}$ & $0,209^{*}$ & $0,197^{*}$ & $0,164^{*}$ & $0,165^{*}$ & 0,132 \\
2007 & 0,055 & 0,055 & 0,049 & 0,059 & 0,094 & 0,080 & 0,082 \\
2008 & $-0,041$ & $-0,041$ & $-0,015$ & $-0,014$ & 0,008 & 0,011 & 0,000 \\
2009 & 0,044 & 0,044 & 0,018 & 0,022 & 0,011 & 0,015 & 0,028
\end{tabular}




\begin{tabular}{cccccccc}
2010 & 0,042 & 0,042 & 0,054 & 0,074 & 0,056 & 0,059 & 0,026 \\
2011 & 0,068 & 0,067 & 0,032 & 0,036 & 0,032 & 0,046 & 0,049 \\
2012 & $0,312^{*}$ & $0,310^{*}$ & $0,275^{*}$ & $0,284^{*}$ & $0,289^{*}$ & $0,278^{*}$ & $0,218^{*}$ \\
2013 & 0,082 & 0,082 & 0,058 & 0,099 & 0,080 & $0,010^{*}$ & 0,084 \\
2014 & 0,079 & 0,079 & 0,052 & $-0,093$ & $-0,072$ & $-0,069$ & $-0,273$ \\
2015 & 0,082 & 0,082 & 0,044 & $-0,089$ & $-0,059$ & $-0,066$ & $-0,019$ \\
\hline
\end{tabular}

SUL

Tabela 14 - Painel de Efeitos Fixos - I de Moran dos resíduos das microrregiões clube sul de 2004 a 2015.

\begin{tabular}{cccccccc}
\hline \multirow{2}{*}{ Ano } & \multicolumn{7}{c}{ Matriz Espaciais } \\
\cline { 2 - 8 } & Q1 & R1 & K3 & K5 & K7 & K10 & K20 \\
\hline 2004 & $0,627^{*}$ & $0,627^{*}$ & $0,578^{*}$ & $0,575^{*}$ & $0,562^{*}$ & $0,529^{*}$ & $0,498^{*}$ \\
2005 & $0,610^{*}$ & $0,611^{*}$ & $0,564^{*}$ & $0,558^{*}$ & $0,547^{*}$ & $0,513^{*}$ & $0,482^{*}$ \\
2006 & $0,610^{*}$ & $0,610^{*}$ & $0,558^{*}$ & $0,562^{*}$ & $0,541^{*}$ & $0,505^{*}$ & $0,467^{*}$ \\
2007 & $0,610^{*}$ & $0,611^{*}$ & $0,561^{*}$ & $0,561^{*}$ & $0,547^{*}$ & $0,519^{*}$ & $0,487^{*}$ \\
2008 & $0,666^{*}$ & $0,667^{*}$ & $0,614^{*}$ & $0,612^{*}$ & $0,600^{*}$ & $0,572^{*}$ & $0,540^{*}$ \\
2009 & $0,563^{*}$ & $0,564^{*}$ & $0,508^{*}$ & $0,509^{*}$ & $0,482^{*}$ & $0,458^{*}$ & $0,420^{*}$ \\
2010 & $0,663^{*}$ & $0,664^{*}$ & $0,613^{*}$ & $0,610^{*}$ & $0,595^{*}$ & $0,564^{*}$ & $0,528^{*}$ \\
2011 & $0,657^{*}$ & $0,658^{*}$ & $0,602^{*}$ & $0,601^{*}$ & $0,587^{*}$ & $0,555^{*}$ & $0,520^{*}$ \\
2012 & $0,677^{*}$ & $0,679^{*}$ & $0,624^{*}$ & $0,622^{*}$ & $0,608^{*}$ & $0,579^{*}$ & $0,543^{*}$ \\
2013 & $0,654^{*}$ & $0,655^{*}$ & $0,599^{*}$ & $0,600^{*}$ & $0,587^{*}$ & $0,556^{*}$ & $0,523^{*}$ \\
2014 & $0,617^{*}$ & $0,618^{*}$ & $0,572^{*}$ & $0,567^{*}$ & $0,553^{*}$ & $0,524^{*}$ & $0,496^{*}$ \\
2015 & $0,627^{*}$ & $0,628^{*}$ & $0,579^{*}$ & $0,576^{*}$ & $0,567^{*}$ & $0,538^{*}$ & $0,505^{*}$ \\
\hline
\end{tabular}

Nota: * Significante ao nível de $1 \%$

Fonte: Resultado da pesquisa.

Tabela 15 - Painel SDM Efeitos Fixos - I de Moran dos resíduos das microrregiões clube sul de 2004 a 2015.

\begin{tabular}{cccccccc}
\hline \multirow{2}{*}{ Ano } & \multicolumn{7}{c}{ Matriz Espaciais } \\
\cline { 2 - 8 } & $\mathrm{Q} 1$ & $\mathrm{R} 1$ & $\mathrm{~K} 3$ & $\mathrm{~K} 5$ & $\mathrm{~K} 7$ & $\mathrm{~K} 10$ & $\mathrm{~K} 20$ \\
\hline 2004 & $0,219^{*}$ & 0,078 & $-0,005$ & 0,050 & 0,045 & 0,042 & 0,043 \\
2005 & $0,202^{*}$ & 0,076 & $-0,002$ & 0,066 & 0,030 & 0,016 & 0,025 \\
2006 & $0,210^{*}$ & $0,271^{*}$ & $-0,003$ & $0,239^{*}$ & $0,208^{*}$ & $0,191^{*}$ & $0,167^{*}$ \\
2007 & $0,135^{*}$ & $-0,048$ & $-0,000$ & $-0,052$ & $-0,015$ & $-0,022$ & $-0,009$ \\
2008 & 0,096 & 0,014 & $-0,008$ & 0,040 & 0,056 & 0,053 & 0,036 \\
2009 & 0,037 & 0,042 & $-0,002$ & 0,033 & 0,028 & 0,031 & 0,033 \\
2010 & $0,251^{*}$ & 0,066 & $-0,001$ & $0,092^{*}$ & 0,073 & 0,070 & 0,033 \\
2011 & $0,237^{*}$ & 0,091 & $-0,000$ & 0,060 & 0,051 & 0,057 & 0,052 \\
2012 & $0,480^{*}$ & $0,036^{*}$ & $-0,001$ & $0,348^{*}$ & $0,333^{*}$ & $0,312^{*}$ & $0,236^{*}$ \\
2013 & $0,200^{*}$ & $0,145^{*}$ & $-0,000$ & $0,171^{*}$ & $0,144^{*}$ & $0,151^{*}$ & 0,125 \\
2014 & $-0,033$ & 0,080 & $-0,000$ & $-0,090^{*}$ & $-0,069$ & $-0,066$ & $-0,024$ \\
2015 & $-0,038$ & 0,009 & 0,000 & $-0,078$ & $-0,051$ & $-0,058$ & $-0,013$ \\
\hline
\end{tabular}

Nota: * Significante ao nível de $1 \%$

Fonte: Resultado da pesquisa. 